\section{NOVA TELLVS}

\section{kyth}

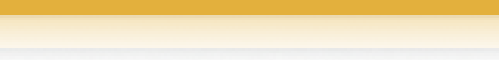

MOLINA, José

Jámblico, Epístola a Macedonio acerca del destino

Nova Tellus, vol. 23, núm. 2, 2005, pp. 163-218

Centro de Estudios Clásicos

Distrito Federal, México

Disponible en: http://www.redalyc.org/articulo.oa?id=59120933006

- Cómo citar el artículo

- Número completo

- Más información del artículo

- Página de la revista en redalyc.org
Centro de Estudios Clásicos

México
Nova Tellus

ISSN: 0185-3058

novatelu@servidor.unam.mx 


\title{
Jámblico, Epístola a Macedonio acerca del destino
}

\author{
José Molina \\ Universidad Nacional Autónoma de México \\ josemolina@correo.unam.mx
}

RESUMEN: Este trabajo pretende contribuir a la reconstrucción de la doctrina acerca del destino planteada por el filósofo sirio Jámblico, mediante una versión de los fragmentos de una carta que aquél escribiera a un tal Macedonio en que se ocupaba de este tema. En el apéndice se presentan también otros textos y sus traducciones, tomados del Protréptico a la filosofía, del tratado Acerca de los misterios egipcios, de Jámblico, y del tratado Acerca de los dioses y del mundo, de Salustio.

\section{$* * *$}

ABSTRACT: This discussion seeks to contribute to the reconstruction of the doctrine on fate of the Syrian philosopher Iamblichus, through a translation of the fragments of a letter that he wrote to a certain Macedonian, who was concerned with this subject. The Appendix presents some further texts and translations taken from Iamblichus' Protreptic to Philosophy, and his treatise On the Egyptian Mysteries, as well as Sallustius' treatise On the Gods and on the World.

Palabras Clave: destino, epístola, jámblico, macedonio.

RECEPCIÓN: 26 de junio de 2005.

ACEPTACIÓN: 2 de agosto de 2005. 



\title{
Jámblico, Epístola a Macedonio acerca del destino
}

\author{
José Molina
}

\section{El destino en el pensamiento de Jámblico}

Mediante la versión de los fragmentos de una carta que escribiera a un tal Macedonio, ${ }^{1}$ intento participar en la reconstrucción de la doctrina acerca del destino planteada por el filósofo sirio Jámblico (ca. 242-326 d. C.).

Pero antes de pasar a la lectura de esos fragmentos, me ha parecido importante añadir como preámbulo algo sobre los antecedentes de tal misiva, y la exposición de lo que el mismo autor ha dicho en torno al destino en otras obras; de esa manera podrá tenerse un marco que permita mirar esas líneas dentro de un mejor horizonte hermenéutico.

Como bien se sabe, no es el destino un tema marginal de la literatura o de la filosofía griegas, que convoque meramente ánimos melancólicos a su discusión. Por el contrario, en él se cifran visiones teológicas, cosmológicas y antropológicas, que

\footnotetext{
* Este artículo fue elaborado dentro de los proyectos PAPIIT IN407705 y CONACYT 40891-H.

${ }^{1}$ Cfr. Stob., I, 80-81; II, 173-175. Aunque B. Dalsgaard Larsen consigna los fragmentos como de dos distintas epístolas, él mismo reconoce que es difícil saber si no pertenecen a una sola (cfr. Dalsgaard Larsen, I, pp. 50 s., n. 90). Existe traducción francesa de la Epístola a Macedonio, en E. Léveque, ap. M. N. Bouillet, Les "Ennéades" de Plotin, II, Paris, 1859, pp. 670-672, citada en Des Places, 1966, p. 6, n. 7; y traducción al inglés, en Johnson, pp. 117-119. Daniela Patrizia Taormina trabaja actualmente en la edición de los fragmentos jambliqueanos que aparecen en Estobeo.
} 
tienen serias consecuencias éticas. ${ }^{2}$ En otras palabras, así como se verifica en los tratados que se conservan al respecto, al tema del destino permanecen unidos el de la providencia y el del libre arbitrio. Si bien es cierto que, según Albrecht Dihle, "hay elementos indicadores de que durante mucho tiempo, la incompatibilidad de los supuestos fundamentales de libertad y necesidad ni fue resentida ni reconocida como tal", ${ }^{3}$ los problemas surgidos de esa incompatibilidad apremiaron sobre todo a los filósofos de la época helenística, y confrontaron a las distintas escuelas, principalmente a platónicos y a estoicos. Quizá, de acuerdo con Cicerón en su tratado Acerca del destino - donde acaso expresa la opinión de Antíoco de Ascalón-, los conflictos entre unos y otros consistían básicamente en problemas de nomenclatura; por último, las incompatibilidades entre libertad y necesidad, es decir, entre destino y libre arbitrio, no encontraron un planteamiento claro desde el punto de vista filosófico sino gracias a Plotino, y desde el teológico gracias a San Agustín. ${ }^{4}$

En cuanto a los antecedentes del pensamiento jambliqueano habría que tomar en cuenta, por supuesto, a Platón mismo. Éste considera al alma como principio de las acciones, y, en consecuencia, independiente de los factores externos y nacida en el hiperuranio; además, juzga que los elementos infralunares pueden influirla mientras está encarnada, pero no determinarla absolutamente; la filosofía habrá de ser instrumento para su liberación de los ciclos del devenir, o sea, de la iterativa encarnación. En esta visión, el destino estaría constituido por todos los factores no anímicos, dado que el alma debe ser tomada aparte del universo. Así, vemos a Jámblico afirmar

\footnotetext{
${ }^{2}$ Cfr. infra, n. 7.

${ }^{3}$ Cfr. Albrecht Dihle, "Liberté et destin dans l'antiquité tardive", en Revue de théologie et de philosophie, 121, 1989, p. 130, citado en Tapia Zúñiga, Pedro C., y Martha E. Bojórquez Martínez, "Introducción”, en Plutarco, p. XXXVI.

${ }^{4}$ Cfr. Tapia Zúñiga, op. cit., p. XXXIX.
} 
que el destino es "la naturaleza del universo". ${ }^{5}$ Otros antecedentes, más cercanos a Jámblico, podrían ser los tratados homónimos Acerca del destino del pseudo-Plutarco y el del peripatético Alejandro de Afrodisias. El objetivo central del primero parece que es afirmar la libertad del hombre, por oposición al determinismo de los estoicos, recurriendo a los peripatéticos, a los académicos y a los estoicos mismos $;{ }^{6}$ el del peripatético Alejandro de Afrodisias, igualmente se opone no sin ironía a los argumentos de la escuela estoica, con el fin de presentar la doctrina aristotélica del destino. ${ }^{7}$ No hay que

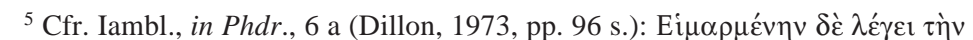

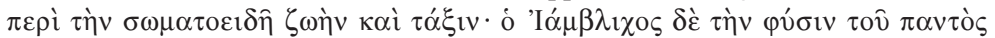

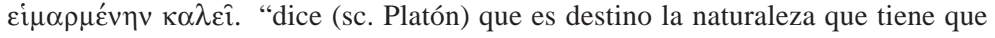
ver con la vida y con el orden corporiformes. Y Jámblico llama destino a la naturaleza del universo".

${ }^{6}$ Cfr. Tapia Zúñiga, op. cit., pp. XXX-XXXIX.

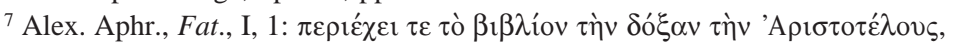

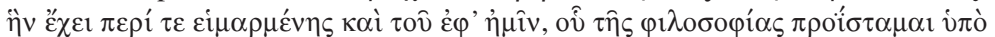

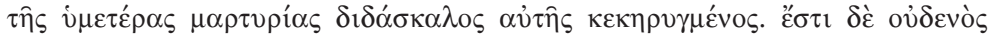

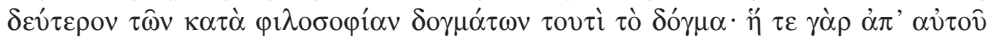

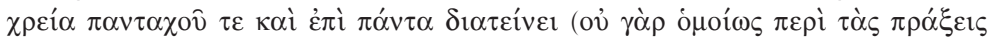

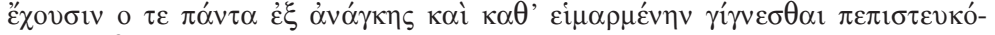

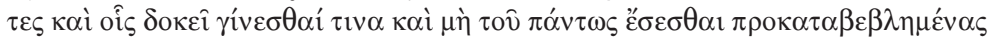

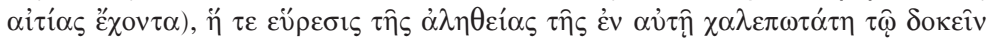

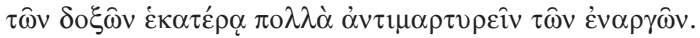

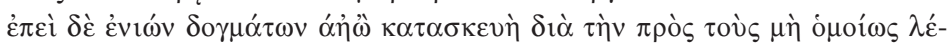

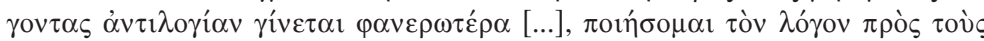

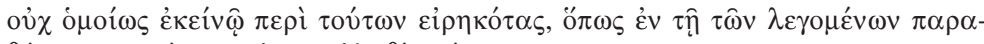

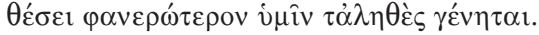

"El libro contiene la opinión que acerca del destino y de nuestra responsabilidad tiene Aristóteles, de cuya filosofía estoy al frente, proclamado por vuestro testimonio como maestro. Esta doctrina no está como segunda de ninguna de las doctrinas en filosofía; en efecto, la utilidad que se desprende de ella está en todas partes y se extiende a todo (pues no de la misma manera son respecto de sus acciones los que han creído que todo se produce necesariamente y de acuerdo con el destino, y aquellos a los que les parece que algunas cosas se producen incluso no teniendo causas para existir absolutamente), y el descubrimiento de la verdad que existe en ella es el más difícil por el hecho de que muchas de las cosas evidentes parecen dar antitestimonio de cada una de las opiniones.

"Ya que la organización de algunas doctrinas se vuelve más clara por la contradicción con respecto a quienes no hablan de la misma manera [...], empren- 
olvidar tampoco que entre la literatura frecuentada por Jámblico, como se deja ver en su obra Acerca de los misterios egipcios,${ }^{8}$ está lo que se conoce como el Corpus Hermeticum, donde a propósito del destino se lee el siguiente diálogo con Poimandres, la mente de la soberanía absoluta:

"Entonces”, afirmo yo, "los elementos de la naturaleza, ¿por qué subsistieron?"

—De nuevo, aquél [sc. Poimandres] respondió a esto: "A causa de la voluntad de dios, la cual, habiendo tomado la Palabra y habiendo visto el bello cosmos, lo imitó, habiéndose hecho ella un cosmos mediante sus propios elementos y sus criaturas que son almas. El Intelecto dios, siendo hermafrodito, existiendo como vida y luz, parió con la palabra otro Intelecto creador, el cual, siendo dios del fuego y del hálito, creó siete gobernadores que rodean en círculos el cosmos sensible, y el gobierno de ellos se llama 'destino",".

El análisis del origen de estas doctrinas, si es helénico, específicamente platónico, o si en verdad acusan un sustrato auténticamente egipcio, no puede ser abordado en este momento. Cabe destacar, sin embargo, que el destino está limitado al orden natural del universo, al "cosmos sensible", según se

deré el tratado con respecto a los que no han hablado de la misma manera que aquél respecto a estas cosas, a fin de que, en la presentación de lo que se dice, lo verdadero se vuelva más claro para vosotros" (trad. de Ricardo Salles y José Molina, sin publicar).

${ }^{8}$ Cfr. Iambl., Myst., VIII. La edición más autorizada del texto griego, de momento, sigue siendo la de Des Places, 1966. Las últimas traducciones son: Clarke y Moreschini.

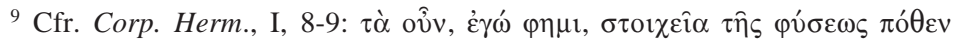

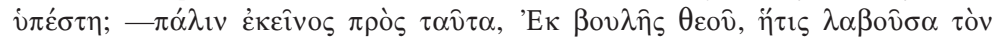
$\Lambda$ ó

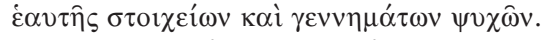

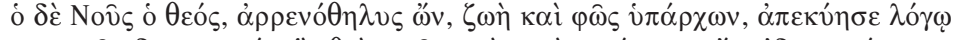

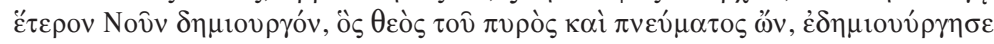

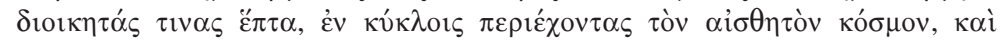

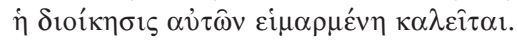


dijo; y puede añadirse también que ese gobierno séptuplo no es sino el de los astros que rodean la tierra, a quienes cierta astrología hace responsable de todo lo que ocurre entre los hombres.

Por lo demás, el antecedente irrebatible de la doctrina jambliqueana sobre el destino, lo constituye el primer tratado de la tercera Enéada, de Plotino. Allí, el egipcio Plotino (ca. 204270 d. C.) rebate las opiniones deterministas de los atomistas, de los estoicos, tanto el determinismo radical de Zenón como el moderado de Crisipo, y las doctrinas de los astrólogos; señala al alma como causa de las acciones; distingue las acciones del alma, de acuerdo con su estado, bien cuando está unida al cuerpo, bien cuando es independiente de él. Del mismo modo, el alma tiene actos voluntarios e involuntarios, y son virtuosos quienes llevan a cabo acciones nobles y libres.

Todos estos antecedentes: Plotino, el Corpus Hermeticum, Alejandro de Afrodisias, el pseudo-Plutarco, y hasta el propio Platón, además de merecer estudios por separado, junto con otras fuentes, pueden no dar razón última de la doctrina de Jámblico.

De acuerdo con Proclo, Jámblico escribió lo que podría considerarse un tratado sobre el destino y la providencia; ${ }^{10}$ pero, al igual que muchas de sus obras, ésa en que se ocupaba de dichos temas está perdida. Otras fuentes marginales de su doctrina, excepción hecha de la Epístola a Macedonio, son las siguientes: 1) algunas líneas del Protréptico a la filosofía, donde se refiere poco más de una opinión, en apariencia pitagórica, a propósito del destino; ${ }^{11}$ 2) un texto, por cierto más extenso, en el escrito conocido como Acerca de los misterios

${ }^{10}$ Cfr. Procl., De Prov., III, 5: hoc quidem enim Iamblichus in hiis que de providentia et fato mille accessibus elaboravit. Puede pensarse, naturalmente, que las líneas que Proclo consagra al tema de la distinción entre providencia y destino, están en estrecha relación con la obra jambliqueana.

${ }^{11}$ Cfr. Iambl., Protr., 3. 
egipcios, ${ }^{12}$ donde se trata, para decirlo con mayor precisión, de la doctrina que supuestamente los egipcios sostienen en cuanto al destino; ${ }^{13}$ y 3) unas líneas más de la epístola de Jámblico a Sopatro, ${ }^{14}$ conservadas en las Églogas, del obispo Juan de Estobeo. ${ }^{15}$

Como es obvio, a partir de los textos que llegaron hasta nosotros no es fácil hacer un discurso continuo y coherente de la doctrina de Jámblico acerca del destino; pues la obra dedicada deliberadamente a ese tema, la Epístola a Macedonio, también se encuentra en estado fragmentario.

Cabe tomar en cuenta, además, el tratado Acerca de los dioses y del mundo de Salustio, pues éste basó su composición en el pensamiento jambliqueano; ${ }^{16}$ allí, en el capítulo noveno, se expone una síntesis de la doctrina sobre el destino, a la luz de la cual puede leerse también la epístola de Jámblico.

A continuación, presento aunque sea muy esquemáticamente el contenido de estas "fuentes marginales de la doctrina jambliqueana acerca del destino", ${ }^{17}$ porque considero que pueden funcionar como un importante antecedente que permitirá una mejor comprensión de los fragmentos de dicha epístola.

${ }^{12}$ Ya es cosa sabida que el título de esta obra es Respuesta del maestro Abamón a la epístola de Porfirio a Anebón, y soluciones de las dificultades que se encuentran en ella. Jámblico se vale de un pseudónimo, cfr. B. Dalsgaard Larsen, I, pp. 47 s.

${ }^{13}$ Cfr. Iambl., Myst, VIII, 6-8.

${ }^{14} \mathrm{Cfr}$. Stob., I, 81. Véase, además, supra, n. 5, donde se encuentra otro pequeño vestigio de la doctrina jambliqueana del destino en su Comentario al Fedro.

${ }^{15}$ Stobi era una ciudad antigua, cuyas ruinas se encuentran en la actual PustoGradsko; en la Macedonia que formaba parte de la antigua Yugoslavia.

${ }^{16}$ Cfr. Gabriel Rochefort, "Introduction", en Saloustios, p. XXVIII: "un estu-

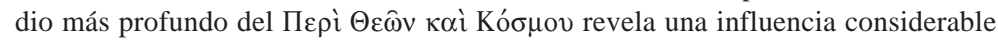
de los dogmas neoplatónicos en su generalidad, de las doctrinas de Jámblico para los análisis más precisos, y del pensamiento de Juliano, que domina el conjunto". Des Places señala que Salustio comparte la visión de Jámblico acerca del destino, en contra de la de Plotino y Porfirio, cfr. Des Places, 1966, p. 23.

${ }^{17}$ Estos textos, con su traducción, aparecen al final de este artículo. 


\section{El destino en el Protréptico a la filosofía}

Se trata, más bien, sólo del capítulo tercero del Protréptico a la filosofía, el cual es el segundo de un total de diez libros que componían la Colección de las doctrinas pitagóricas, paideia filosófica, bajo los auspicios de un pitagorismo renovado. En ese capítulo se menciona un método de exhortación a la filosofía que se sirve de los Versos dorados, obra acaso del siglo II d. C., que se atribuía, empero, a Pitágoras. Los tópicos de esos versos son los siguientes: 1) la práctica de aquella virtud que permite al hombre alejarse de la naturaleza humana y llegar a la esencia y a la virtud divinas; 2) la sabiduría contemplativa, que abarca el conocimiento divino y humano; 3) el estudio de la naturaleza y la contemplación del cielo, que permiten el conocimiento de lo que necesariamente debe suceder; 4) los hombres, que son responsables de sus actos y se hacen a sí mismos felices o desdichados; 5) el bien, que es connatural a la naturaleza humana, y el abandono de los males, que exhorta a la filosofía, la cual es "preparación para la muerte" y liberación del alma a la vida en sí misma; 6) repudio de los males; 7) contraposición entre la actividad intelectual uniforme y la sustancia incidental; 8) persuasión a la perfección divina, y 9) modo de transformar al hombre en dios.

Aunque se pudiera hacer lectura de este capítulo, con ánimo de ser breve, aunque todos estos tópicos están implicados entre sí, sólo quiero llamar su atención en los temas que juzgo más pertinentes al destino.

Si uno lee distraídamente ese tercer capítulo tiene la falsa impresión de estar ante meros lugares comunes; los solos versos que se citan bastan para ello; sin embargo, interesa sobre todo el comentario que Jámblico hace de ellos, donde fijándose un poco más descubre uno su aportación. Señala la naturaleza del alma humana, la cual esencialmente está preparada para "divinizarse"; no hay que olvidar que gran parte del ideal 
filosófico radicaba en asimilarse con dios, merced a las actividades intelectuales. En el tópico 3) se señala que el conocimiento del mundo, que es el ámbito inalienable del destino, permite la previsión de los acontecimientos. Es decir, el mundo, y consecuentemente el destino, su ordenamiento, es conocible. Después, Jámblico llamará la atención, al comentar los siguientes versos:

conocerás que, voluntarias penas teniendo, los hombres son desdichados; si lo bueno está cerca, no lo perciben ni lo oyen; de lo malo la salida pocos conocen

en que los hombres aparecen allí como soberanos de sus actos, y en ellos, Pitágoras afirmaría que "nosotros elegimos nuestro destino, que nosotros somos nuestra suerte y demonio, y que nos hacemos felices a nosotros mismos". Sin duda, esta doctrina está en consonancia con la enseñanza platónica de la República, donde en célebre pasaje se les dice a las almas:

A ustedes no las escoge su demonio, por el contrario, ustedes eligen su demonio. La primera que elija escogerá primero la vida que llevará necesariamente. La virtud no tiene dueño, a la cual, más o menos, honrando y deshonrando, cada uno participará de ella. Lo culpable viene de lo que se escoge, dios es inocente. ${ }^{18}$

Más adelante, Jámblico hace acaso una alusión a la piedra rodante con que Crisipo se refería al destino, según la noticia que nos llegó de Aulo Gelio (Gell., VII, 2). Dice Jámblico:

Es intolerable que los hombres, semejantes a piedras que ruedan, aquí y allá sean llevados, teniendo infinitas desgracias.

En otras palabras, el hombre, en su más profunda realidad puede ser dueño de sus acciones y liberarse del destino. Como se verá luego, también es importante el comentario que hace Jámblico de los siguientes versos, en el tópico 7):

${ }^{18}$ Cfr. Pl., R., X, 617 e $1-5$. 
La discordia es fatal compañera que a ocultas nos hiere, connatural: no hay que alentarla, mas huir de ella, cediendo.

\section{Al respecto comenta Jámblico:}

También aquí, el poeta muestra lo doble de la naturaleza humana y a ese extraño ser viviente que está adherido a nosotros desde el nacimiento, al cual unos llaman bestia policéfala; otros, vida mortal, y otros, naturaleza generativa. Aquí la nombra "discordia connatural", no porque tenga la misma categoría de nuestra existencia más excelsa, sino porque está al lado, como compañera, de la existencia más digna. Recomienda huir de ella y colocar en su lugar, sin cortapisas, la actividad intelectual uniforme que, en vez de dañar, hace bien; en vez de precipitar hacia la destrucción, proporciona el principio de la salvación; arroja fuera, como si se tratara de algo que no nos pertenece, a esa sustancia incidental y de segundo rango que nos acompaña, y, a cambio, da lugar a la existencia fundamental y más perfecta, que tiene todo a partir de sí misma y en sí misma. Por esta razón, es conveniente reducir a aquél acompañante a lo más pequeño, y acrecentar esta forma de vida hasta lo más grande. De esta manera, esta exhortación llega a ser la más eficaz para llevar una vida conforme a los principios del intelecto.

Lo importante es ese aspecto doble de la naturaleza humana; en Acerca de los misterios egipcios, Jámblico hablará de "dos almas": una está sometida al destino; la otra, de naturaleza inteligible, es elevada por los dioses mismos a su ámbito intelectual. Cabe señalar aquí el papel prominente que tiene el intelecto para liberarse del destino, subrayado por Jámblico en su comentario, en aparente contradicción con lo que haría ver en el tratado Acerca de los misterios egipcios, ${ }^{19}$ lo cual comentaremos a continuación.

\footnotetext{
${ }^{19}$ Cfr. Trouillard (pp. 98-141) ha llegado a decir que cabe preguntarse, por este motivo, si en verdad el autor de las dos obras es el mismo. Sin embargo, la autoría jambliqueana del De mysteriis, parece hoy incontestable, cfr. Stäcker, pp. 15-16.
} 
El texto tomado de la obra jambliqueana Acerca de los misterios egipcios, VIII, 6-8, presenta otras características que hay que tomar en cuenta. Se trata de la exposición hermética con respecto al sentido que tendría el hecho de que lo que depende de nosotros esté vinculado a los movimientos de los astros. Si bien Plotino había distinguido dos momentos de la acción del alma: uno, cuando está unida al cuerpo, y otro, cuando está separada de él. ${ }^{20}$ Jámblico habla aquí de dos almas: la primera, proveniente del primer inteligible y que participa de la potencia del demiurgo, y la otra, recibida a partir de la revolución de los seres celestes. La primera es la que puede liberarse del destino, y aquí viene la doctrina que distingue a Jámblico. Esta alma inteligible se libera del destino, retorna junto con los dioses inteligibles; por su vida al lado de los dioses, realiza las obras divinas (i. e., la teúrgia), que la elevan hacia lo inengendrado. La segunda alma es lo que se ha dado en llamar, el "vehículo" del alma, mediante el cual el alma inteligible desciende hacia este mundo; ésta, una vez liberada del destino, abandona su vehículo, que se cree es destruido en ese momento, o bien, es preservado de alguna manera en el cosmos para ulteriores encarnaciones. ${ }^{21}$ Este vehículo, por señalar un dato curioso, también ha sido relacionado con el concepto cristiano del cuerpo resucitado. ${ }^{22}$

En cuanto a la doctrina de las dos almas, cabe recordar el pasaje del Protréptico, cuando habló de lo doble de la naturaleza humana. Aunque aquí se podría decir que es una doctrina egipcia la que se refiere, en X, 5, Jámblico afirma:

\footnotetext{
${ }^{20}$ Cfr. Plot., III, 1, 1-20. También distingue allí Plotino un alma superior de una inferior.

${ }^{21}$ Cfr. infra, n. 48.

${ }^{22}$ Cfr. Stäcker, p. 164.
} 
el ser humano, si se considera divinizado, ${ }^{23}$ unificado ya antes a la visión de los dioses, entró además en otra alma que está adaptada alrededor de la especie humana de forma, y, por esto, llegó a estar en el vínculo de la necesidad y del destino. ${ }^{24}$

Es importante destacar que el estatus ontológico del alma, es decir, su pertenencia al mundo inteligible, separado del destino, es condición necesaria para su liberación, pero no razón suficiente. En efecto, la causa eficiente de su liberación son los dioses, pues son ellos los que la liberan del destino, no las propias facultades del alma.

También hay que hacer notar que son los dioses quienes llevan a cabo el destino, y pueden disolver los males ocasionados por él. Este aspecto se conoce como providencia.

Cabe aclarar aquí que entre las peculiaridades del pensamiento jambliqueano está una valoración más positiva del mundo; en efecto, él llegará a hablar incluso de cierta materia divina. ${ }^{25}$ En el texto en cuestión menciona ciertas "naturalezas" últimas que descienden de los dioses y se entretejen con la generación del cosmos y con el cuerpo. La divinidad se llega, pues, a "mezclar" de algún modo con el universo, pero no a la manera estoica, al punto de identificarse con él.

\footnotetext{
${ }^{23}$ Atendiendo al origen divino del alma, ésta se diviniza cuando abandona el cuerpo y se desprende también a su vez de su "vehículo" (ó $\chi \mu \alpha)$, al cual podría estarse haciendo referencia mediante el "alma" que se menciona en seguida, sujeta al destino y a la necesidad. Sin embargo, aunque el alma toma otra vida y ya no pudiera decirse que se trata de un hombre (cfr. Iambl., Myst., I, 12: غ̇v yò $\rho$

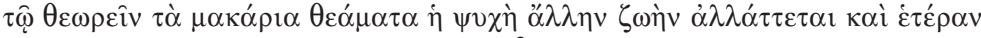

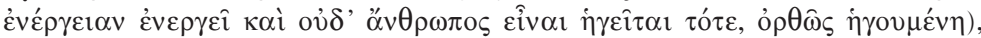
debe considerarse que propiamente hablando el alma no puede "volverse dios".

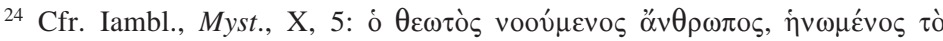

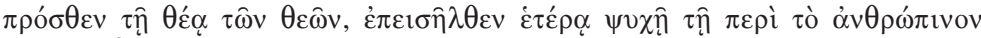

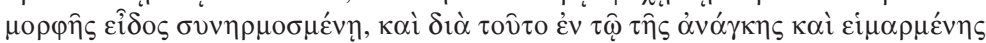

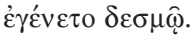

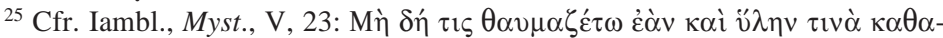

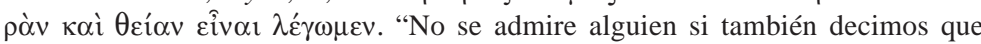
alguna materia es pura y divina, pues habiendo nacido también ésta del padre y demiurgo del todo, posee su perfección adecuada a la recepción de los dioses".
} 
En el último párrafo del capítulo séptimo, conviene subrayar que se refiere literalmente a "otro principio del alma" en geni-

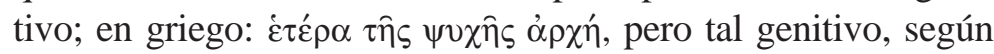
Thomas Stäcker, quien ha realizado el mejor estudio sobre el lugar de la teúrgia en el pensamiento de Jámblico, debe entenderse como genitivo objetivo; en otras palabras, existe otra

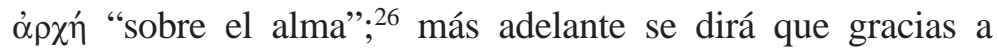

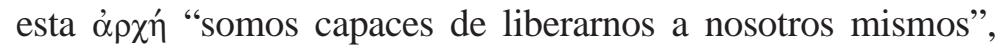
mas ya se ha comentado que son los dioses quienes liberan del destino, de forma que no hay que tomar esta frase en el sentido de que es el hombre mediante sus esfuerzos propios quien se libera de los vínculos de la heimarmene. Al empezar el capítulo octavo, se pregunta Jámblico retóricamente: “¿es posible, mediante los dioses que giran, liberarse a sí mismo?" Después afirma categórico: "en cada uno de los dioses, incluso los manifiestos, hay algunos principios inteligibles de esencia, a través de los cuales se produce para las almas la separación de la generación del cosmos". La doctrina debía de exponerse en otro tratado sobre los dioses que desafortunadamente también está perdido. Allí se explicaría, entre otras cosas, quiénes eran las deidades que elevaban hacia sí a las almas, cómo las liberaban del destino, con cuáles ceremonias. A continuación se habla un poco, precisamente de ellas, de las ceremonias, cuya sagrada institución las hace inmutables.

Aquí cabe hacer énfasis en que al menos algunas de las encarnaciones del alma no se dan porque hubieran cometido cierta falta anterior al nacimiento, sino que algunas son enviadas por dios para que de nuevo regresen hacia él, y, naturalmente, llegado el momento de acuerdo con la distribución de las almas y por el cuidado que el dios tiene de ellas, se dará su liberación de la generación.

Por lo demás, no es éste el único pasaje de esta obra donde se tratan temas vinculados con el destino; sin embargo, me

${ }^{26}$ Cfr. Stäcker, p. 146. 
limito a mencionar algunos ejemplos, que aparecen en otros libros, dado que mi objetivo es estar en condiciones para leer los fragmentos de la Epístola a Macedonio.

Los ejemplos son los siguientes:

En el libro I, capítulo 19, Jámblico se ocupa de la unión entre los dioses incorpóreos, es decir, los dioses, inteligibles, y los dioses manifiestos, o sea, los seres celestes que tienen cuerpo. La esencia de estos últimos sigue siendo incorpórea, inteligible y unificada. El cosmos, ámbito, no se olvide, del destino, está en continuidad con su modelo y unido a él; es una imagen de los paradigmas inteligibles divinos, que a su vez están unidos al Uno. No es ocioso leer este capítulo al lado del fragmento 1 A de la epístola que aquí se estudia.

En el libro IV, Jámblico explica el mal en el mundo, y lo que en apariencia pareciera una injusticia de los dioses cuando hacen sufrir a un hombre. La solución, muy apegada al estoicismo, ${ }^{27}$ es que el mal particular puede no serlo para el conjunto (IV, 8-10), y una vida desgraciada puede ser una vida que está expiando faltas de vidas anteriores; ese conocimiento global del todo y del pasado es prerrogativa, por supuesto, de los dioses.

Sostiene Jámblico en IV, 5, algo que, pienso, puede resultar interesante:

En efecto, si precisamente la comunión de la misma naturaleza en cuerpos y en las almas que están sin cuerpos produce un mismo entrelazamiento en la vida del cosmos, y un ordenamiento común, también es necesario que el pago de la pena sea reclamado al conjunto, y máxime cuando la grandeza de las injusticias que se han dado antes por una sola excede la satisfacción de una sola del castigo consecuente a los delitos. ${ }^{28}$

\footnotetext{
${ }^{27}$ Cfr. Von Arnim, II, 937, 1169-1170, 1178.

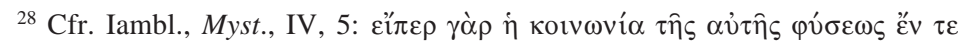

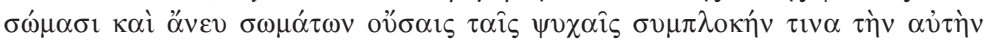

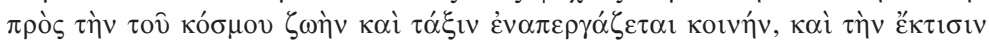


En el libro IX, trata otro tema muy vinculado con el destino: el demon propio. Éste tiene el objetivo de ayudar al hombre mientras está sujeto al destino; pero si el ser humano ha hecho cuanto depende de él para liberarse del destino, mediante la virtud y la actividad intelectual, al final ese demon propio entrega el alma al cuidado de un dios, que es quien lo libera del destino.

\section{El destino en la Epístola a Sopatro (Stob., I, 81)}

En cuanto al fragmento de la Epístola a Sopatro (Stob., I, 81), en el cual también se alude al destino, es tan pequeño, que vale la pena citarlo completo:

La esencia del destino está toda en la naturaleza. Y digo naturaleza a la causa inseparable del cosmos y que inseparablemente rodea las causas enteras de la generación; todo cuanto, separadamente, las esencias y disposiciones superiores comprenden en sí mismas. Por tanto, es vida corporiforme y razón que incide en la generación, las formas implicadas en la materia y la materia misma, la generación compuesta a partir de estos factores, y el movimiento que cambia todo, y la naturaleza que administra ordenadamente lo que se genera, y los principios y los fines y las producciones de la naturaleza, y las vinculaciones de éstos entre ellos, y sus travesías desde el principio hasta el final, cumplen el destino. ${ }^{29}$

Finalmente, antes de leer directamente la Epístola a Macedonio, vale la pena decir algunas cosas del fragmento donde Salustio, en el tratado Acerca de los dioses y del mundo, IX, habla sobre el destino, en referencia al pensamiento de Jámblico.

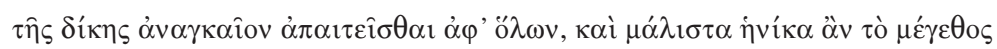

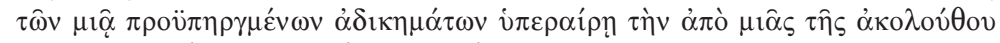

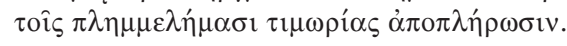

${ }^{29} \mathrm{El}$ texto griego aparece en el apéndice de este artículo. 
Los primeros tres números hablan, más bien, de la providencia, que se descubre en el orden del mundo, en la teleología. Una prueba ulterior, según Salustio, son los oráculos y los remedios a las calamidades provocadas por la naturaleza. Ahora bien, la providencia la ejercen los dioses sin fatiga y, algo que es interesante, sin deliberación. ${ }^{30}$ A partir del número 4 se refiere al destino como otro tipo de providencia que surge de los cuerpos y reside en ellos. A ésta se le puede conocer, dice Salustio, mediante el arte matemático. Es plausible que tal aserción se deba también a Jámblico. No debe olvidarse que, con base en lo que queda de su obra, sabemos que este pensador tuvo como proyecto la "pitagorización de la filosofía", 31 lo cual, dicho de otra manera, significa una matematización de la filosofía. Al respecto, conviene agregar que Jámblico muy platónicamente consideró al alma como un estatus intermedio entre el mundo material y el orden inteligible, siendo al mismo tiempo paradigma de aquél e icono de éste, cuyo modo propio de conocimiento era precisamente el matemático. ${ }^{32}$ Claro que las matemáticas en este contexto tienen un sentido muy amplio, que incluye la aritmética, la geometría, la música y la astronomía. Precisamente esta matemática era el contenido de su Colección de las doctrinas pitagóricas. Poco importa que la intención de Jámblico de matematizar el conocimiento del universo, es decir, el conocimiento del destino, haya quedado como algo programático. Al respecto Sambursky anota:

el hecho de que las concepciones de Jámblico tengan sus raíces en Platón, no desmerece la originalidad de su pensamiento, y sus realizaciones no deben subestimarse por el hecho de que se haya mantenido como algo puramente programático. En la historia de

\footnotetext{
${ }^{30}$ Cabría quizá la aclaración que para Plotino una vida que puede elegir, que

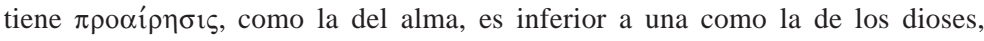
que nunca tendra la opción de hacer el mal, cfr. Rist.

${ }^{31}$ Cfr. O' Meara, 1992.

32 Jámblico trata de los objetos matemáticos, sobre todo en el De communi mathematica scientia, analizado por Merlan; véase también O’ Meara, 1990; Steel.
} 
las ideas, el nivel programático es un paso esencial de una concepción que se desarrolla hacia la realización práctica. Los que logran por primera vez llegar a la clara formulación de un programa, pueden, por algún motivo inherente a la historia o por mero accidente, preceder durante siglos enteros al cumplimiento de ese programa. El extraordinario plan de Jámblico para la física teórica fue sugerido en el año 300, y tuvo que esperar casi mil cuatrocientos años para que empezara su realización. Francisco Bacon, quien tampoco era un científico creador, logró formular un programa para las ciencias experimentales, cuya realización empezó en el siglo en que murió. A diferencia de Jámblico, tuvo la suerte de vivir en una civilización que estaba en su apogeo, cuando la tradición y continuidad del pensamiento comenzaba a arraigar. ${ }^{33}$

Siguiendo con el texto, Salustio también atribuye al mérito, y no a fuerzas ciegas del destino, el éxito y el fracaso. Afirma en 5 la doctrina de la bondad divina inalienable, y, concordando con lo que dice Jámblico en Acerca de los misterios egipcios (I, 18), los supuestos males que se desprenden de las acciones divinas deben atribuirse a la mala aptitud de quien recibe y no a los seres divinos. En 6 rechaza el determinismo astral. En 7 habla de la suerte, con una concepción inusitada. El irónico dicho del poeta Juvenal, según el cual nuestra ignorancia hace diosa a la fortuna ${ }^{34}$ toma un sentido casi literal. La suerte o lo espontáneo adquiere otra valoración; la suerte es una divinidad que tiene su ámbito de acción en el mundo infralunar. En su tratado Acerca de la Vida pitagórica, Jámblico relata que los pitagóricos:

creían que nada ocurre a partir de lo espontáneo ni de la suerte, sino de acuerdo con la providencia divina, sobre todo a los hombres buenos y piadosos. ${ }^{35}$

\footnotetext{
${ }^{33}$ Cfr. Samboursky, pp. 79 s.

${ }^{34}$ Cfr. Juv., XIV, 315-316: Nullum numen habes, si sit prudentia; nos te, / nos facimus, Fortuna, deam. "Ningún divino poder tienes, si existe prudencia; nosotros, nosotros te hicimos, Fortuna, diosa".

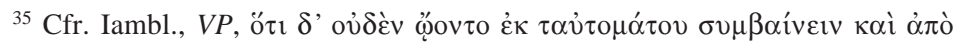

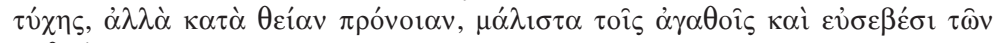
$\dot{\alpha} v \theta \rho \dot{\pi} \pi \omega v$.
} 
Dicho en otras palabras, lo espontáneo y la suerte, como se verá en la Epístola a Macedonio, son otras formas de la providencia. Los acontecimientos espontáneos y fortuitos tienen como causa a un dios o a un demon. También, por esta alusión a la suerte, se ve que Salustio sigue muy de cerca las doctrinas de Jámblico.

\section{El destino en la Epístola a Macedonio}

Un último preámbulo me parece necesario, para que la comprensión de la lectura de esta misiva pueda ser más provechosa, y es la descripción breve y sumaria de los siete fragmentos de distinta extensión que se han conservado. Podrá resultar claro, además, de acuerdo con lo que se ha visto hasta ahora, que los temas de tales fragmentos eran los principales de su doctrina, dado que coinciden, aunque a veces siendo mucho más explícitos, más reveladores, también más densos o más sugerentes, con los contenidos que acerca del destino se vislumbraban en las otras obras.

El primero aparece separado de los otros seis. Es un fragmento de un fuerte carácter metafísico. Muy semejante al otro fragmento que ya se mencionó de la Epístola a Sopatro, en él se hace ver la vinculación que todos los seres y las causas tienen con el Uno, y cómo el destino, al mismo tiempo que se vincula con el Uno, abarca y unifica a todos los órdenes naturales.

Los demás pasajes aparecen juntos en Estobeo. Por tratarlos como un conjunto, comienzo de nuevo la enumeración.

El primero habla sobre la esencia del alma. En principio, libre del destino, puede, sin embargo, darse a sí misma y subordinarse a sí misma a la revolución del todo; entonces es llevada por el destino. Sus actividades propias, afianzadas a lo divino, a lo bueno y a lo inteligible, pueden, con todo, ser independientes de la naturaleza. 
El segundo fragmento insiste en el deber que se tiene de vivir de acuerdo con el intelecto y en dependencia de los dioses, pues una tal vida entrega "el poder sin dueño del alma", y nos libera de los vínculos de la necesidad; es decir, nos hace vivir una vida divina, ya no meramente "humana".

En el tercero, particularmente extenso en comparación con los otros, se hace ver, en primer lugar, cómo incluso los movimientos de la fatalidad tienen un vínculo con el orden inteligible e incorruptible. El destino está en contacto con la providencia. En segundo término se afirma que el origen de las acciones humanas está separado de la naturaleza, y que dicho origen contribuye en la disposición del destino, la completa y la utiliza. Finalmente, se asienta que el alma está liberada de lo exterior, por la razón pura que hay en ella, pero que, igualmente, puede vincularse con la disposición del cosmos, por proyectar su vida hacia la generación.

En el cuarto fragmento de la epístola, Jámblico establece que lo espontáneo y la suerte no eliminan el orden ni la continuidad de las causas, ni la unificación de los principios ni el dominio de los seres primeros. La suerte misma es supervisor y factor de la cohesión de los distintos órdenes, a veces un dios, otras, un demon.

El quinto, no tan breve como el segundo, ni tan extenso como el tercero, habla de la bondad intrínseca de la virtud, y de lo indiferente que son los bienes, su posesión o su carencia, para completar la óptima naturaleza del hombre.

El sexto y último de los fragmentos abunda sobre la idea del precedente. El alma, siendo intelectual e inmortal, encuentra en la vida divina, lo bello, lo bueno y su fin. La naturaleza mortal ni contribuye ni estorba a su perfección de vida o a su felicidad. 


\section{JÁMBLICO \\ EPÍSTOLA A MACEDONIO ACERCA DEL DESTINO}

Textos griego y español 
(Stob., I, 80 s.)

$1 \mathrm{~A}$

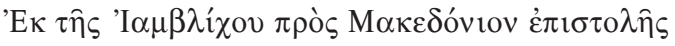

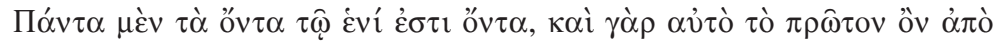

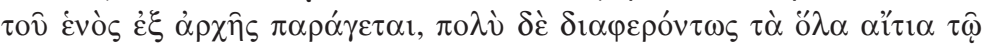

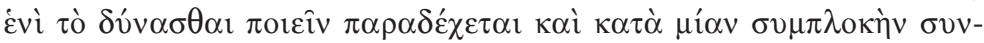

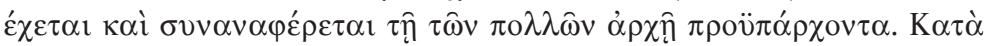

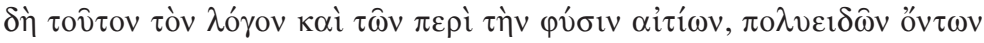

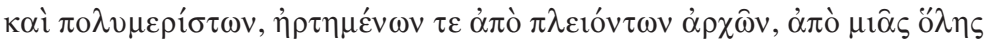

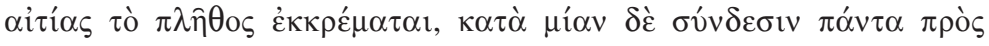

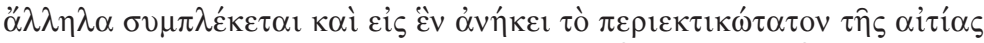

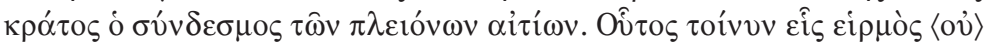

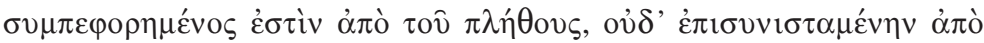

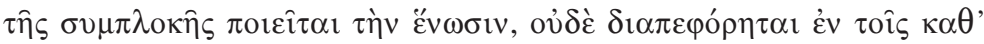

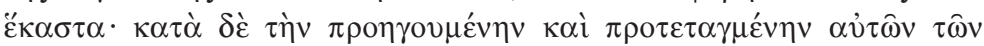

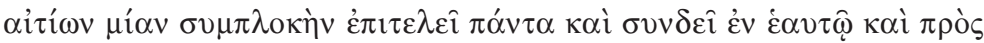

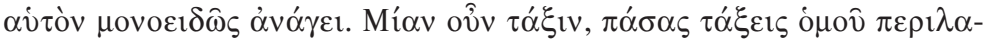

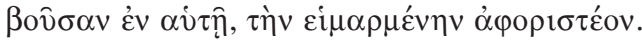

(Stob., II, 173-175)

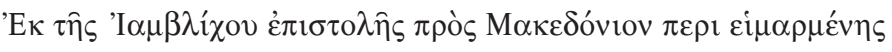

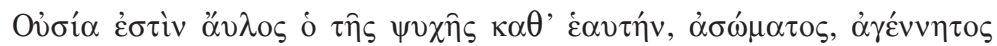

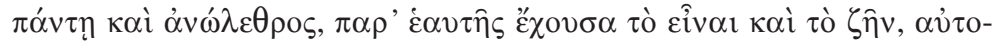

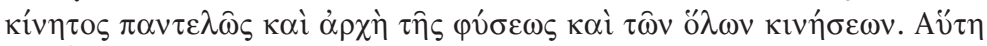

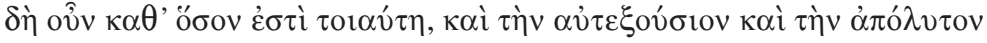

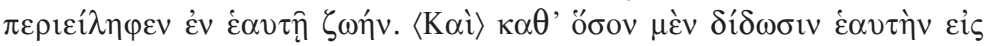

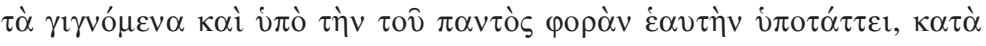

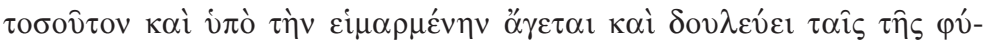

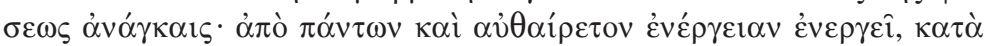

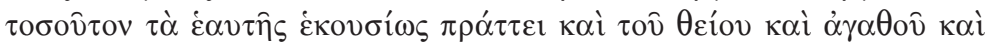

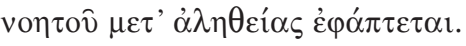

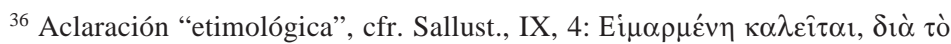

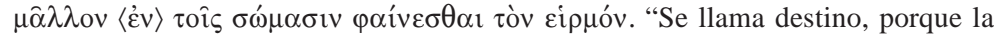
concatenación aparece más en los cuerpos".
} 
(Stob., I, 80 s.)

$1 \mathrm{~A}$

De la Epístola de Jámblico a Macedonio

Todos los seres son seres por el Uno; así, también el primer existente mismo se deriva del Uno, desde el principio; muy particularmente todas las causas reciben del Uno el poder de producir, se mantienen unidas por un solo entrelazamiento y, junto con el origen de la multiplicidad, se consideran como preexistentes. De acuerdo con este razonamiento, también la multitud de las causas naturales - multiformes y múltiples, y ligadas a muchísimos orígenes-, depende de una sola causa única, entrelaza a unas con otras, con un solo vínculo, a todas las cosas, y remite hacia el Uno, que es la más comprehensiva de las causas, la conjunción de las muchísimas causas. Así pues, esta concatenación ${ }^{36}$ no está conjuntada como una a partir de dicha multitud, ni hace sólida a la unificación a partir del entrelazamiento, ni se dispersa en los particulares, sino que realiza todo de acuerdo con el único entrelazamiento anterior y antepuesto a las causas mismas, y vincula en sí misma a todas las cosas y las lleva uniformemente hacia sí misma. Por tanto, hay que definir el destino como un orden único, que al mismo tiempo comprehende en sí mismo a todos los órdenes.

(Stob., II, 173-175)

1

De la Epístola de Jámblico a Macedonio acerca del destino

Por obtener de sí misma el ser y el vivir, la esencia del alma en sí misma es inmaterial, incorpórea, absolutamente increada e indestructible; se mueve absolutamente por sí misma, y es principio del crecimiento y de todos los movimientos. Ésta, por tanto, en cuanto que es tal, abarca en sí misma tanto a la vida autónoma como a la absoluta. Y en la medida en que se da a sí misma a los seres que han de existir y se subordina a sí misma bajo la revolución del todo, en esa medida también es llevada por el destino y sirve a las necesidades de la naturaleza: realiza su actividad incluso independientemente de todas las cosas, en la medida en que hace voluntariamente lo que le es propio, y está enlazada con la verdad de lo divino y bueno e inteligible. 


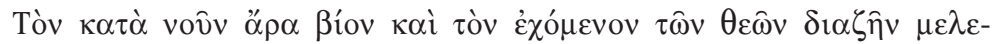

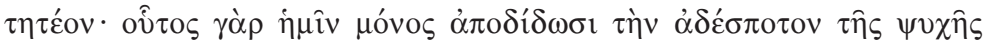

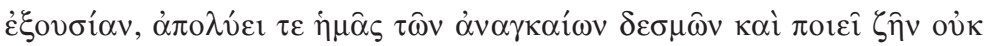

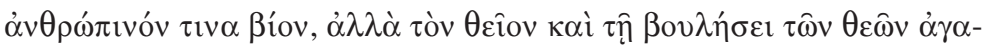
$\theta \omega \hat{\omega} v \dot{\alpha} \pi \circ \pi \lambda \eta \rho о v ́ \mu \varepsilon v o v$.

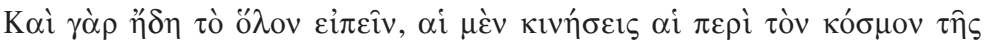

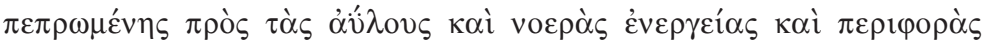

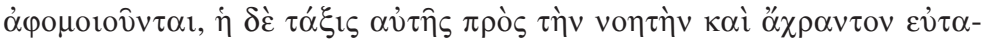

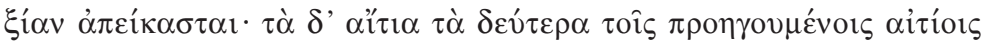

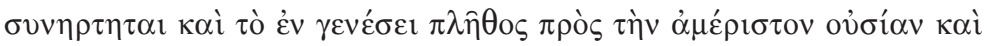

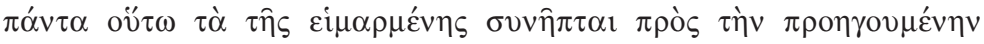

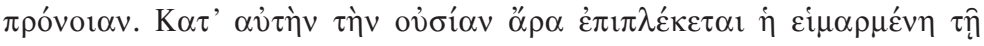

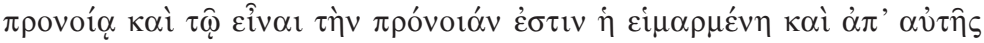

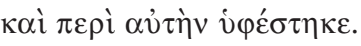

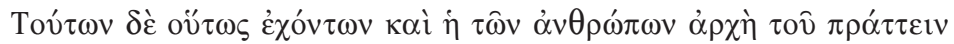

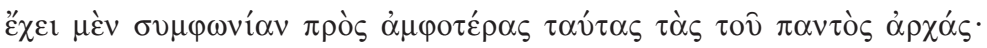

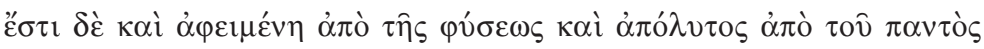

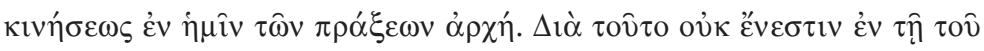

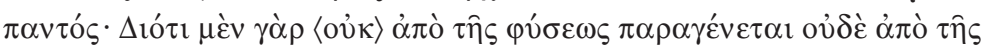

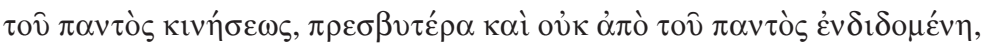

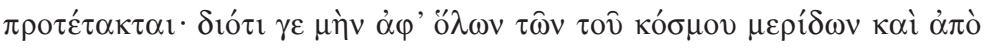

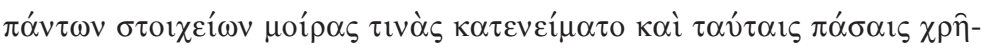

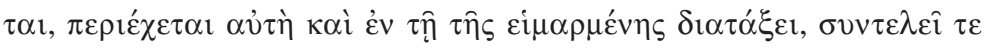

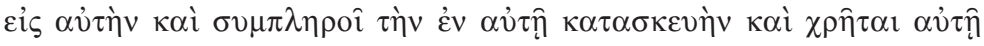

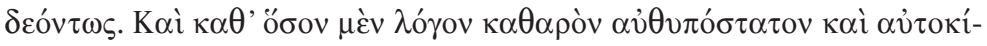

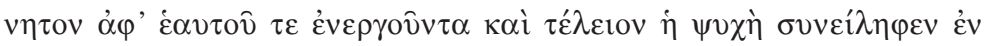

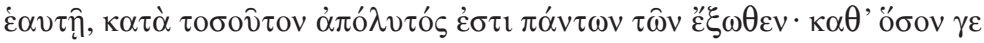

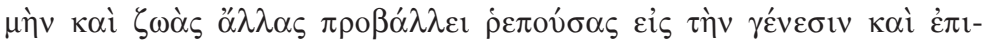

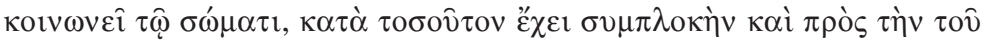

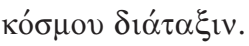


Por tanto, hay que ejercitarse en vivir la vida que es según el intelecto y que está cercana a los dioses, pues sólo ésta nos devuelve el poder independiente del alma, y nos libera de los vínculos de las necesidades, nos hace vivir no cierta vida humana, sino la divina y, por designio de los dioses, llena de bienes.

Pues, para decirlo en general, los movimientos del destino que se refieren al cosmos se asemejan a las actividades y revoluciones inmateriales e intelectuales, y su orden puede compararse con el buen orden inteligible e incorruptible: las causas posteriores se cohesionan con las causas anteriores, y como la multitud en la generación se anuda a la esencia indivisible, así también todo lo propio del destino, con la providencia anterior. El destino, pues, de acuerdo con la esencia misma, se entrelaza con la providencia, y por el hecho de que existe la providencia, el destino desciende de ella y subsiste en torno a ella.

Siendo así estas cosas, también el principio humano del actuar tiene consonancia con estos dos principios del universo, pues en nosotros existe un principio de las acciones separado de la naturaleza y liberado del movimiento del universo. Por eso no está en el principio del universo: por ello ni sobreviene a partir de la naturaleza ni, aunque es más venerable y no entregado por el universo, se pone al frente del movimiento del universo. Por eso ciertamente, a partir de las partes todas del cosmos y de todos los elementos, distribuyó ciertas porciones, y utiliza a todas éstas, él mismo está rodeado también en la disposición del destino, contribuye en ella y completa la constitución que hay en ella y la utiliza necesariamente. Y en la medida en que el alma comprende en sí misma una razón pura, subsistente y móvil por sí misma, que actúa por sí misma y perfecta, en esa medida está liberada de todo lo exterior. Ciertamente, también en la medida en que proyecta otras vidas que se inclinan hacia la generación, y las tiene en común con el cuerpo, en esa medida tiene una ligadura también con la disposición del cosmos. 


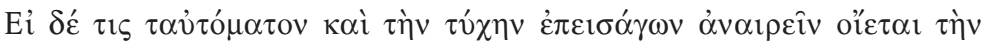

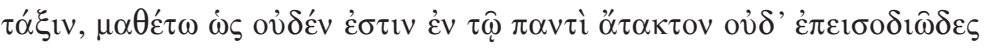

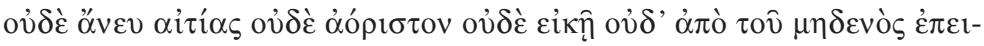

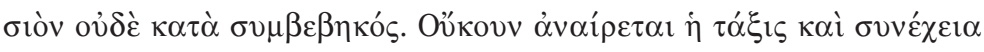

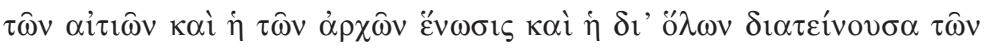

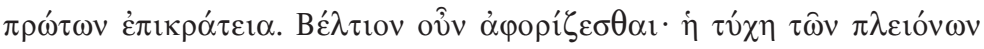

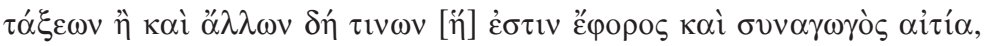

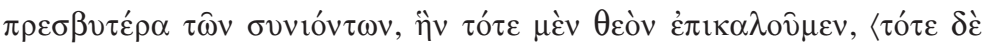

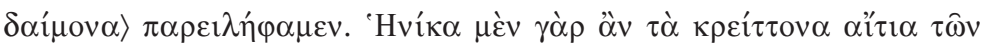

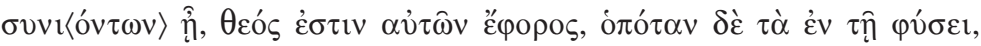

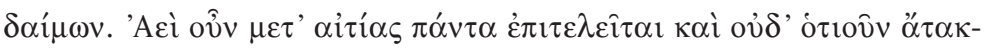

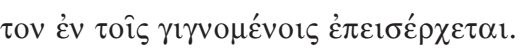

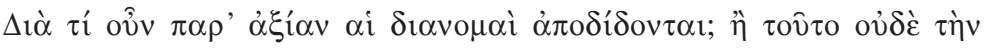

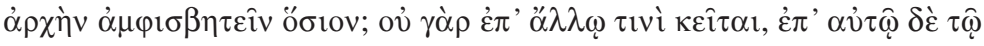

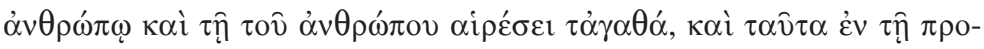

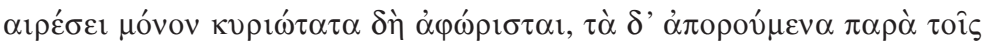

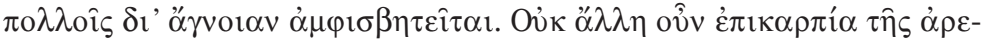

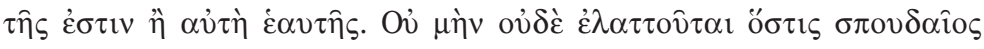

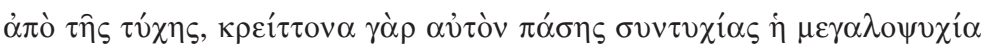

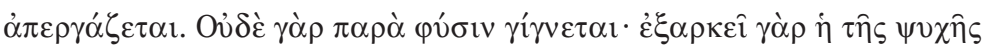

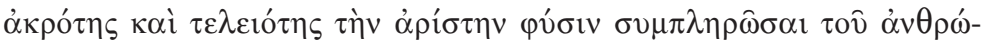

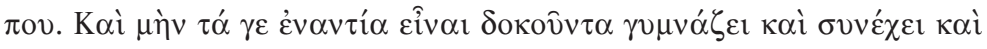

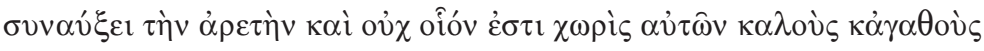

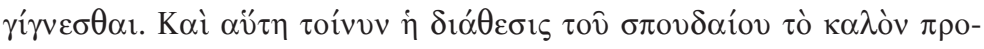

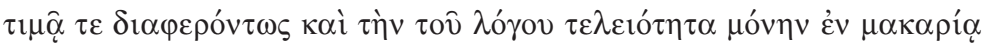

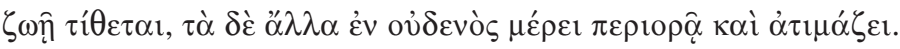


Si alguno, introduciendo lo espontáneo y la suerte, cree eliminar el orden, aprenda que nada en el universo es desordenado ni episódico ni sin causa ni indeterminado ni al azar, ni sucedido por nada ni por accidente. Ciertamente no elimina ni el orden ni la continuidad de las causas ni la unificación de los principios ni el dominio de los seres primeros que se extiende a través de todas las cosas. Por tanto es mejor delimitar: la suerte, de la mayoría de los órdenes o incluso de algunas otras cosas, es causa vigilante y cohesionante, más venerable que los sucesos, a la cual a veces invocamos como dios, y otras, la asumimos como un demon. En efecto, cuando los seres superiores son la causa de los sucesos, un dios es su vigilante, pero cuando son los seres que están en la naturaleza, un demon. Por tanto, siempre todo se lleva a cabo con una causa, y absolutamente nada se introduce sin orden en los seres que han de generarse.

5

¿Por qué entonces las retribuciones se entregan sin mérito? ¿O en principio tampoco es santo dudar de esto? En efecto, los bienes no dependen de ningún otro ser, sino del hombre mismo y de la elección del hombre, y, entonces, sólo en la preferencia, estos bienes quedan definidos como importantísimos, pero se duda de otros, puesto que por ignorancia son problemáticos para la mayoría. Por tanto no hay otro fruto de la virtud que ella de sí misma. Y ni siquiera disminuye quien es virtuoso por suerte, pues la magnanimidad lo hace superior a cualquier circunstancia. En efecto, tampoco sucede contra natura, pues basta la excelencia y perfección del alma para completar la óptima naturaleza del hombre. Y, ciertamente, las cosas que parecen ser contrarias ejercitan, continúan e incrementan la virtud, y no es posible sin ellas que los hombres se vuelvan hermosos y buenos. Así pues, también esta disposición del virtuoso prefiere distinguidamente lo bello, y sólo la perfección de la razón lo pone en una vida dichosa, pero considera las demás cosas en una parte de nada, y las desestima. 


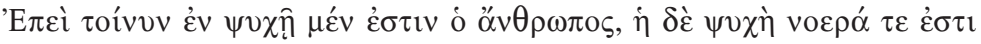

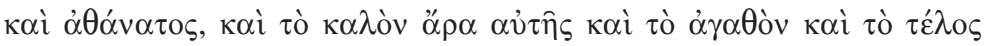

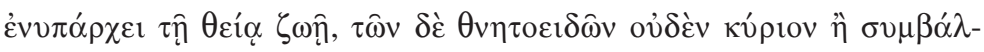

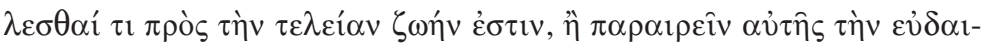

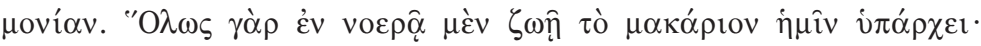

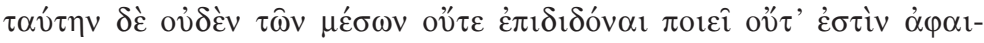

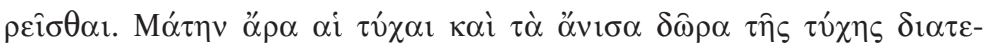

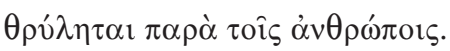


6

Así pues, dado que el hombre está en un alma, y el alma es intelectual e inmortal, por tanto también lo bello y lo bueno y el fin de ella están presentes en la vida divina, y ninguna de las cosas de naturaleza mortal tiene poder o para contribuir en algo para la vida perfecta, o para quitar su felicidad. En efecto, para nosotros lo dichoso está totalmente en una vida intelectual, y ninguno de los medios hace que ésta se entregue, ni puede eliminarla. Por tanto, en vano las suertes y los desiguales dones de la suerte, entre los hombres, se propagan. 


\section{APÉNDICE}

\section{IAMB $\Lambda$ IXOY

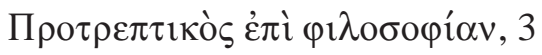

$\langle\Pi \varepsilon \rho \grave{\tau} \tau \hat{\omega} v \alpha i \gamma v \pi \tau i ́ \omega v \mu v \sigma \tau \eta \rho i \omega v\rangle$

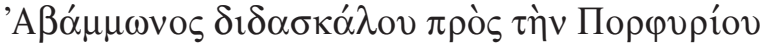

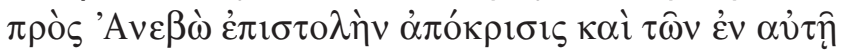

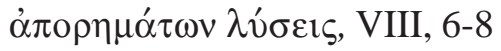

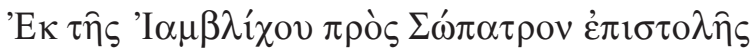
(ap. Stob., I, 81)

\section{$\Sigma \mathrm{A} \Lambda \mathrm{OY} \Sigma \mathrm{TIOY}$}

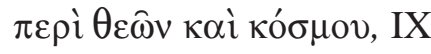




\begin{abstract}
APÉNDICE
Jámblico

Protréptico a la filosofía, 3

$<$ Acerca de los misterios egipcios $>$

Respuesta del maestro Abamón a la epístola de Porfirio a Anebón, y soluciones de las dificultades que se encuentran en ella, VIII, 6-8
\end{abstract}

De la epístola a Sopatro (ap. Stob., I, 81)

Salustio

Acerca de los dioses y del mundo, IX 


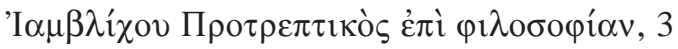

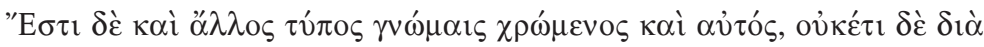

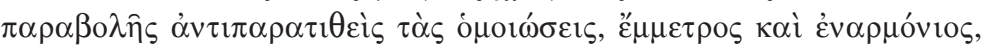

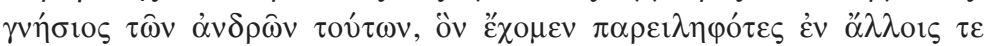

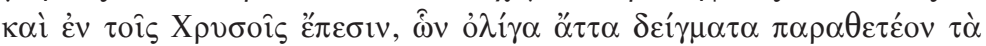
$\tau \mathrm{o} \alpha \hat{\tau} \tau \alpha$.

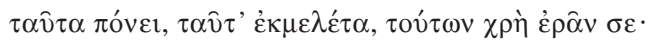

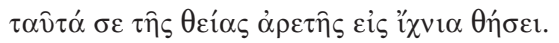

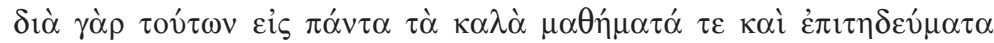

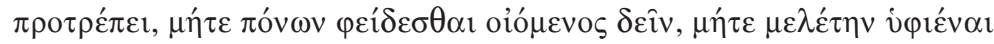

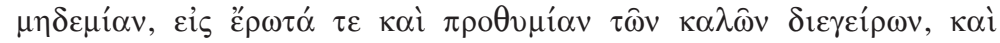

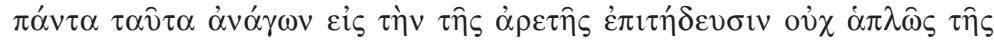

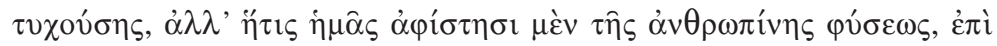

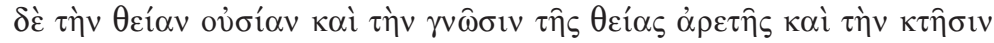

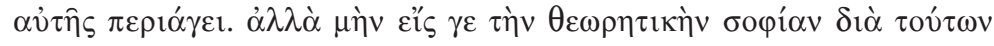
$\pi \alpha \rho \alpha \kappa \alpha \lambda \varepsilon \hat{\imath}$.

$\tau \circ \tilde{\tau} \omega \nu \delta \dot{\varepsilon} \kappa \rho \alpha \tau \dot{\sigma} \sigma \alpha \varsigma$

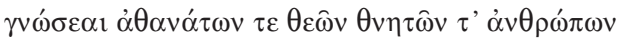

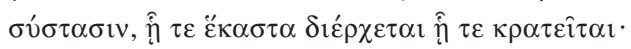

${ }^{37}$ Los Versos Dorados es una obra neopitagórica del siglo II d. C., conformada por versos del pitagorismo antiguo; su objetivo era dar una guía para la vida práctica y social, y garantizar la felicidad en la vida del más allá. Esta cita del Protréptico es la primera que conocemos de la obra; más tarde, el neoplatónico Hierocles escribirá un comentario lleno de veneración, cfr. Van der Horst, pp. XXV-XXXVIII.

38 "esto" se refiere al examen personal que, al acostarse y a veces al levantarse, permite al hombre conocerse a sí mismo, cfr. Iambl., $V P, 256$ : o $\mu$ oí $\omega \varsigma \delta \delta \dot{\varepsilon} \mu \eta \delta$ '

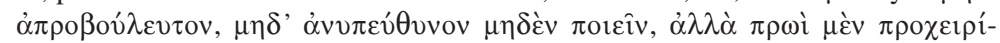

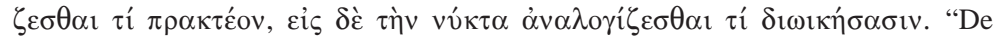
la misma manera, no hacer nada impremeditado o fuera de control, sino en la mañana determinar qué hay que hacer, para analizar en la noche qué han aprovechado". Sin embargo, más que un ejercicio de memoria o de la oposición a las acciones impremeditadas, se trata de evaluar el progreso hecho en la "virtud 


\section{Jámblico, Protréptico a la filosofía, 3}

También existe otra forma de exhortación que utiliza sentencias, pero ya no presenta las semejanzas mediante la comparación; esta forma es rítmica y armoniosa, genuinamente pitagórica; la tenemos porque, entre otras obras, también nos fue transmitida en los Versos Dorados, ${ }^{37}$ de los cuales hay que citar algunos ejemplos como los siguientes:

Esfuérzate en esto, ${ }^{38}$ en esto hazte diestro, debes amarlo: hará que tú sigas, de la virtud divina las huellas.

Mediante estos versos, el poeta exhorta hacia todas las enseñanzas y asuntos nobles, considerando que es necesario no escatimar esfuerzo ni abandonar ningún ejercicio para conseguirlas, estimulando el amor y el deseo de lo bello, y elevando todo hacia la práctica de la virtud, pero no de cualquiera, sino de aquella que nos aleja de la naturaleza humana y nos lleva a la esencia divina, al conocimiento y a la posesión de su virtud.

El poema persuade a la sabiduría teórica a través de estos versos:

$$
\text { de esto }{ }^{39} \text { teniendo dominio, }
$$

conocerás de inmortales dioses y de hombres mortales

la constitución,$^{40}$ cómo atraviesa todo y cómo domina; ${ }^{41}$

divina". Hierocles interpreta estos versos de manera neoplatónica, afirmando que se refieren a la contemplación. "Seguir a Dios" es una idea totalmente pitagórica y el lenguaje de la expresión es épico, cfr. Van der Horst, pp. 23-26.

39 "esto" se refiere al conjunto de las lecciones bellas y sabias, en las cuales el discípulo se ha hecho un experto.

${ }^{40}$ El término $\sigma v ́ \sigma \tau \alpha \sigma ı \varsigma$ puede significar "unión" o "constitución". En el Corpus hermeticum, el sentido de estos versos dentro del poema es la "unión de los hombres y de los dioses"; sin embargo, por la explicación que Jámblico da de tales versos, él entiende la "constitución" de los hombres, como algo aparte de la de los dioses, cfr. Van der Horst, pp. 32-37.

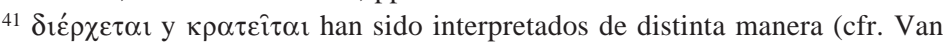
der Horst, pp. 35-37): 1) diferir y parecerse (Hierocles); 2) pasar y afirmarse o

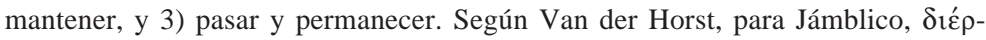




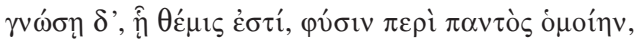

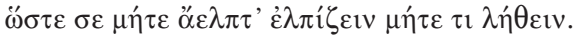

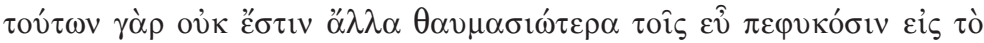

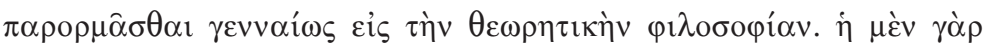

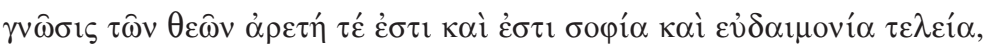

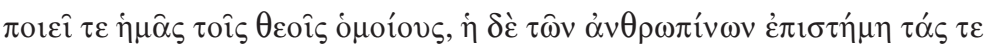

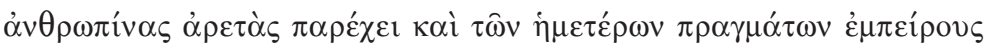

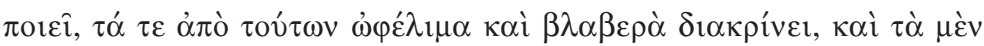

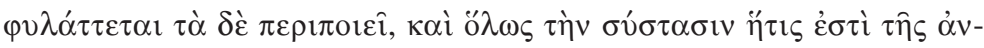

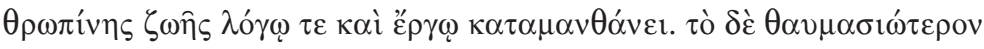

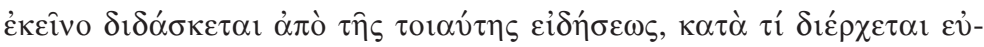

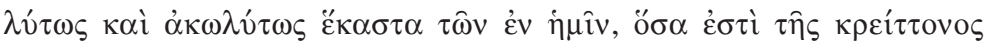

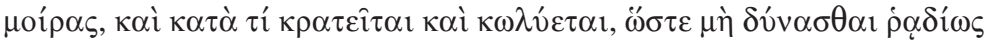

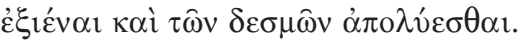

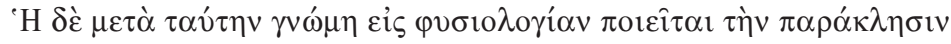

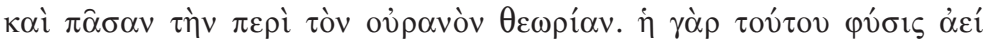

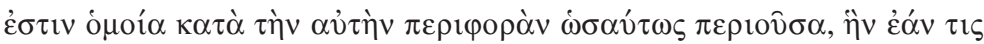

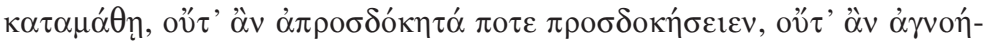

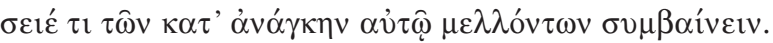

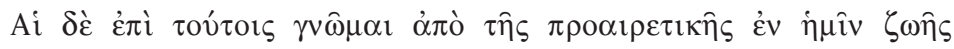

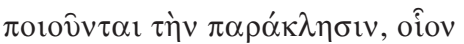

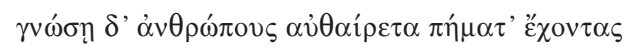

$\tau \lambda \eta \dot{\mu o v \alpha \varsigma}$

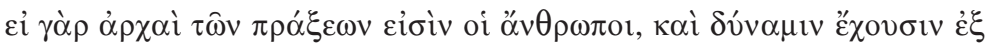

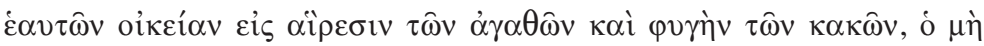

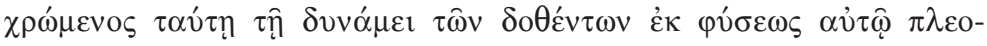

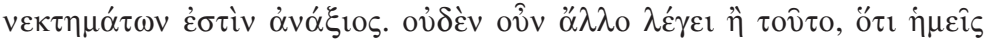

$\chi \varepsilon \tau \alpha_{1}$ "se refiere a las cosas que se continúan en nosotros sin detenerse y sin

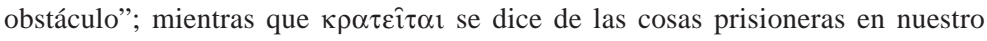
cuerpo terrestre, que no pueden ser liberadas de sus ataduras y por consecuencia no son eternas" (cfr. Van der Horst, p. 37); sin embargo, en la explicación que da Jámblico, el sujeto de ambos verbos es el mismo: "los valores más sublimes"; por mi parte, coincido con Van der Horst en cuanto a $\delta 1 \varepsilon ́ \rho \chi \varepsilon \tau \alpha \iota$, pero en cuanto a $\kappa \rho \alpha \tau \varepsilon i \tau \alpha$, pienso que debe entenderse cómo "se dominan" esos mismos valores. 
sabrás, cuanto es justo, que la esencia ${ }^{42}$ de todo es la misma, de modo que no esperes imposibles, y nada te escape.

No existen otros versos más admirables para quienes, sin vacilar, están bien dispuestos a ser firmemente incitados a la filosofía teórica. Porque el conocimiento de los dioses es virtud, sabiduría y felicidad perpetua, y nos hace semejantes a los dioses; la ciencia de las cosas humanas nos proporciona las virtudes correspondientes, y nos hace expertos en nuestras empresas. De éstas, distingue lo nocivo de lo benéfico; se cuida de lo primero, procura lo último, y examina completamente, con sumo cuidado, de palabra y de obra, la constitución propia de la existencia humana. Sin embargo, lo más maravilloso que se nos enseña a partir de esta doctrina es lo siguiente: en qué medida nos penetran fácil y libremente los valores más sublimes, y cómo hay que señorearlos y arraigarlos, de manera que no se nos escapen fácilmente, y se liberen de sus ataduras.

La sentencia siguiente, que la esencia de todo es la misma, / de modo que no esperes imposibles, y nada te escape, exhorta al estudio de la naturaleza y a la investigación total del cielo. En efecto, la naturaleza del cielo es siempre la misma, es decir, una que gira invariablemente de acuerdo con su movimiento circular, si alguien la estudia, nunca más esperará lo inesperable, ni desconocerá algún hecho de los que necesariamente van a ocurrirle.

Las sentencias siguientes, a partir de la capacidad de elegir que tiene nuestra existencia, procuran la persuasión de esta manera:

Conocerás que, voluntarias penas teniendo, los hombres son desdichados;

En efecto, si los hombres son soberanos de sus actos y tienen por sí mismos capacidad propia para elegir lo bueno y para rechazar lo malo, quien no usa de esta capacidad es indigno de las ventajas que le han sido dadas por la naturaleza. En otras palabras, Pitágoras

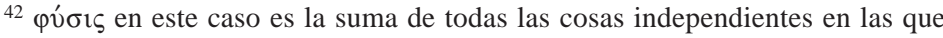
se revela la potencia divina conservadora del mundo; la homogeneidad de los seres se sustenta en la armonía del cosmos; a su vez, esta homogeneidad hace posible el conocimiento, el cual, aunque limitado, hace capaz al hombre de conocer lo oculto (cfr. Van der Horst, pp. 38-41).
} 


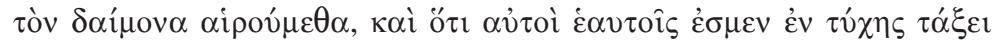

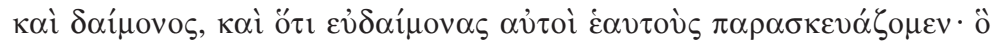

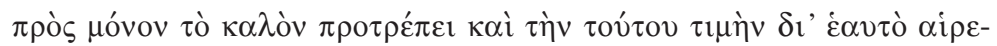

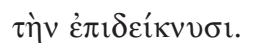

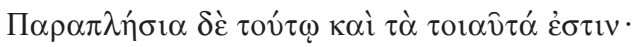

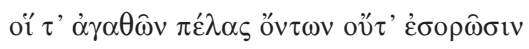

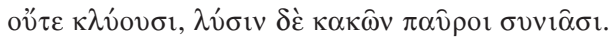

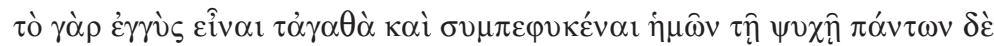

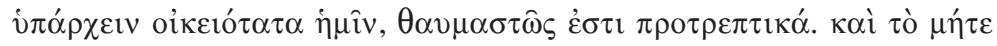

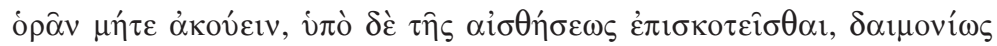

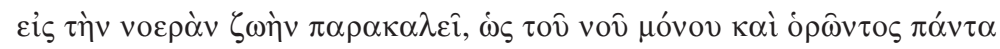

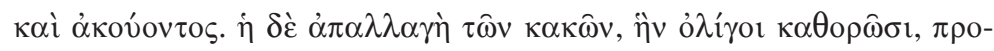

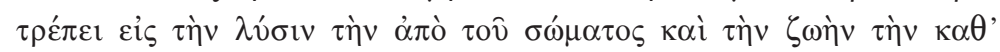

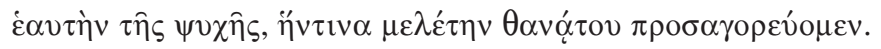

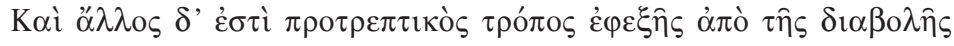

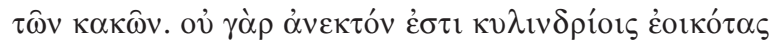

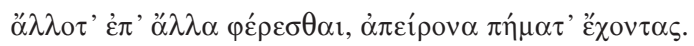

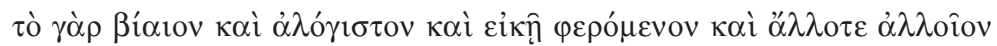

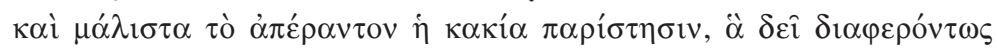

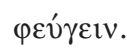

'H $\delta \grave{\varepsilon} \mu \varepsilon \tau \grave{\alpha} \tau \alpha \hat{\tau} \tau \alpha \gamma \nu \omega ́ \mu \eta \hat{\varepsilon} \sigma \tau i ̀ ~ \tau o เ \alpha v ́ \tau \eta$.

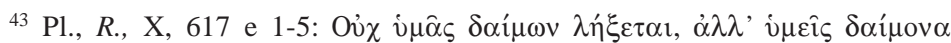

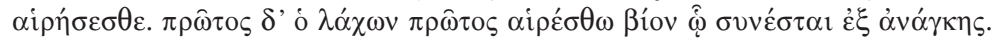

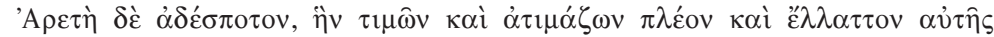

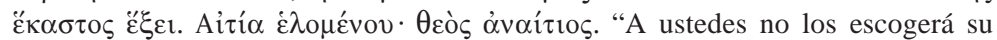
demon; por el contrario, ustedes eligirán su demon. El primero que elija, primero escoja la vida que llevará necesariamente. La virtud no tiene dueño, a la cual, más o menos, honrando y deshonrando, cada uno participará de ella. La culpa es de lo que se escoge, dios es inocente".

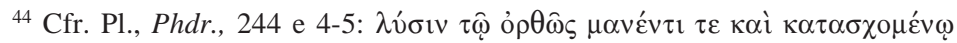

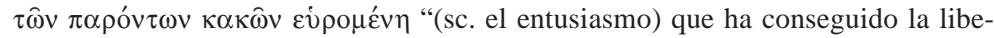
ración de los males presentes para el que ha estado correctamente en el trance y 
dice que nosotros elegimos nuestro destino, que nosotros mismos somos nuestra suerte y demonio, y que nos hacemos felices a nosotros mismos; ${ }^{43}$ este pensamiento exhorta a lo bello como si esto fuera lo único, y demuestra que su valor es deseable por sí mismo.

La sentencia siguiente también es semejante a la anterior:

si lo bueno está cerca, no lo perciben

ni lo oyen; de lo malo la salida pocos conocen. ${ }^{44}$

El hecho de que lo bueno esté cerca de nosotros, sea connatural a nuestra alma y lo más familiar de todo, sirve admirablemente para exhortar. Y el que uno no vea ni oiga, sino que esté en la obscuridad por causa de los sentidos, persuade maravillosamente hacia la vida intelectual, porque sólo el intelecto ve y oye todas las cosas. El abandonar los males, que pocos observan, exhorta hacia la liberación del cuerpo y hacia la existencia de acuerdo con el alma, a lo cual llamamos 'preparación para la muerte'. ${ }^{45}$

Existe otro procedimiento de exhortación que surge del rechazo a los males. Puesto que es intolerable que los hombres, semejantes a piedras que ruedan, ${ }^{46}$

aquí y allá sean llevados, teniendo infinitas desgracias.

Porque la maldad engendra lo violento, lo irracional, lo fortuito, lo extraño y, sobre todo, lo ilimitable, de lo cual es necesario huir, más que de cualquier otra cosa.

La siguiente sentencia es ésta:

poseído"; en este pasaje del Fedro se trata de razas malditas que pagan la pena de alguna falta ancestral, algunos miembros de dichas razas logran escapar de la sanción gracias a la manía.

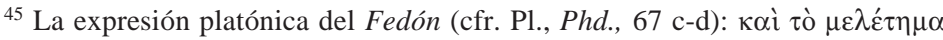

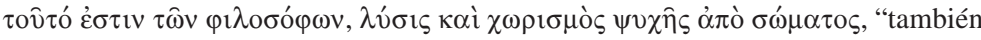
éste es el cuidado de los filósofos: la liberación del alma y su separación del cuerpo", implica que la muerte no debe tomarse en sentido físico, sino como el modo de vida contemplativo, cuya metáfora es "aprender a morir", cfr. Festugière.

${ }^{46}$ Estas piedras rodantes se refieren a una imagen que Crisipo tiene del destino (cfr. Gell., N. A., VII, 2), considerado como una piedra que se desprende de una montaña, cfr. Van der Horst, pp. 44-46. 


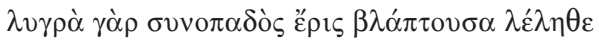

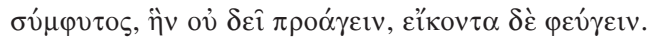

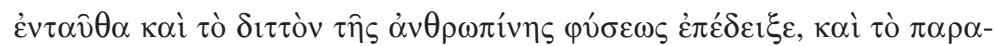

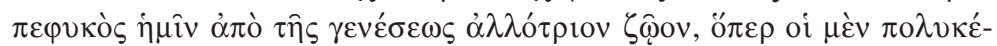

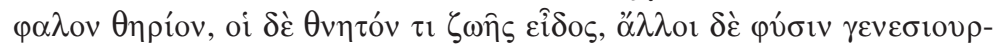

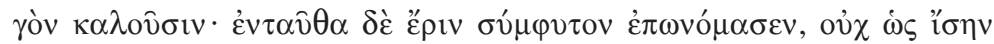

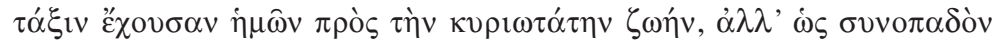

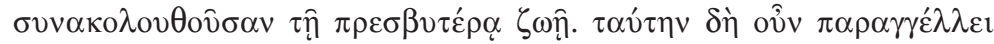

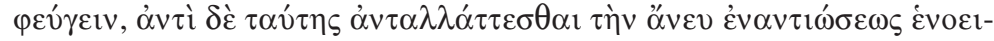

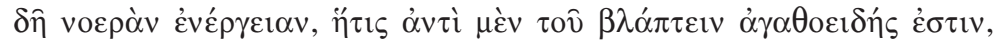

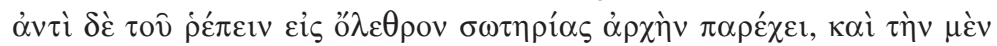

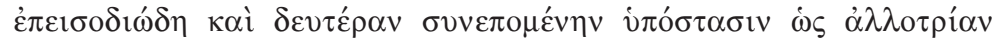

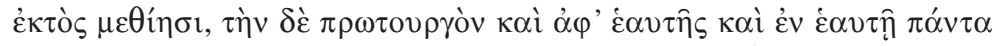

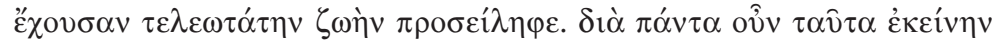

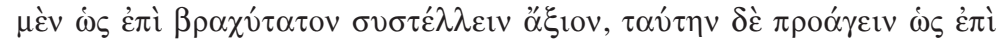

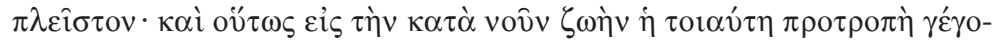

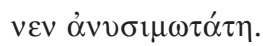

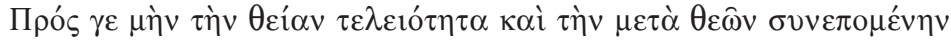

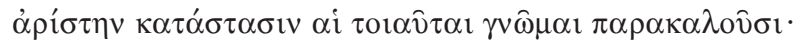

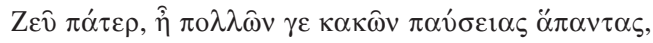

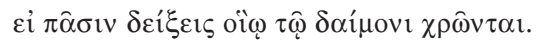

47 "Epıs designa o una discordia entre dios y el hombre, una resistencia a la voluntad divina (Hierocles, Empédocles), o bien, una discordia interior del alma

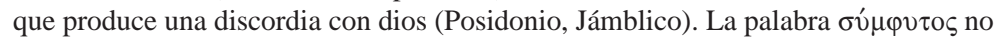
debe tomarse en su sentido ordinario de "innata", sino que en este caso significa "estrechamente ligada", "soldada", cfr. Van der Horst, pp. 46-49.

${ }^{48} \mathrm{Se}$ trata del ő $\chi \mu \alpha$ (vehículo) del alma; ésta es una alusión a Pl., Tim., 42 cd., según la interpretación neoplatónica. Jámblico, de acuerdo a la doctrina caldaica, consideraba que este vehículo del alma no se disolvía después de la muerte, sino que de algún modo sobrevivía dentro del cosmos, cfr. Dillon, 1973, p. 47. El tema es ampliamente tratado en Finamore, 1985.

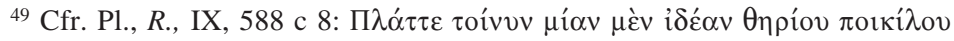

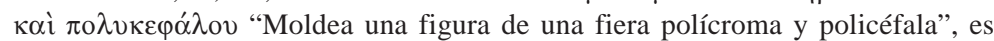
una metáfora de uno de los elementos que, en la antropología platónica, intervienen en la composición del alma humana. Estos elementos eran el apetito concupiscible, la fiera de la que aquí se trata; el apetito irascible, simbolizado con un león, y, por último, la razón, cuya figura era un hombre.

${ }^{50}$ Zeus no sólo era el creador de la vida, sino también el padre de los hombres virtuosos. Jámblico $(V P, 155)$ dice que los pitagóricos invocaban a Zeus como 
La discordia es fatal compañera que a ocultas nos hiere, connatural: ${ }^{47}$ no hay que alentarla, mas huir de ella, cediendo.

También aquí, el poeta muestra lo doble de la naturaleza humana y a ese extraño ser viviente que está adherido a nosotros desde el nacimiento, ${ }^{48}$ al cual unos llaman bestia policéfala; ${ }^{49}$ otros, vida mortal, y otros, naturaleza generativa. Aquí la nombra 'discordia connatural', no porque tenga la misma categoría de nuestra existencia más excelsa, sino porque está al lado, como compañera, de la existencia más digna. Recomienda huir de ella y colocar en su lugar, sin cortapisas, la actividad intelectual uniforme que, en vez de dañar, hace bien; en vez de precipitar hacia la destrucción, proporciona el principio de la salvación; arroja fuera, como si se tratara de algo que no nos pertenece, a esa sustancia incidental y de segundo rango que nos acompaña, y, a cambio, da lugar a la existencia fundamental y más perfecta, que tiene todo a partir de sí misma y en sí misma. Por esta razón, es conveniente reducir a aquél acompañante a lo más pequeño, y acrecentar esta forma de vida hasta lo más grande. De esta manera, esta exhortación llega a ser la más eficaz para llevar una vida conforme a los principios del intelecto.

Los siguientes versos persuaden hacia la perfección divina y hacia la condición más noble, que es propia de los dioses:

Padre Zeus, ${ }^{50}$ en verdad, de muchos males guardarías a todos, si manifestaras a todos la dignidad de sus almas. ${ }^{51}$

salvador ( $\sigma \omega \tau \eta ́ \rho)$ y que a él hacían libaciones antes de comer, cfr. Van der Horst, pp. $53 \mathrm{~s}$. Ahora bien, Jámblico entendía que Zeus no era otro sino el Demiurgo, cfr.

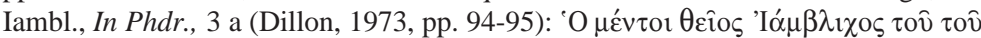

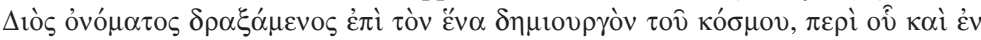

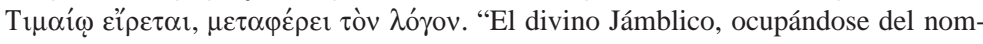
bre de Zeus, refiere el pasaje (sc. Pl., Phdr., 246 e) al único Demiurgo del cosmos, acerca del cual también se habla en el Timeo”. En torno al uso de Jámblico de los dioses de la mitología, puede verse, Zeller, pp. 21-24; Dillon, 1973, pp. 48 s.

${ }^{51}$ Aquí la palabra $\delta \alpha i ́ \mu \omega v$ parece tratarse de una forma de designar el alma, cfr. Van der Horst, pp. 49-53, cfr. Des Places, 1969, p. 117. Un demon era un genio tutelar asignado a cada hombre por los dioses, cuya función era servir al hombre, sobre todo, de intermediario entre el mundo infralunar y el mundo de los dioses, para que el hombre, después de muerto, pudiera atravesar los distintos estados intermedios. Todo hombre debía tratar bien a su demon para conseguir su ayuda, o podía, con un mal comportamiento, hacerlo su enemigo; por eso, la 


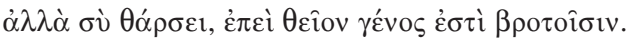

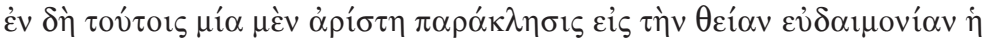

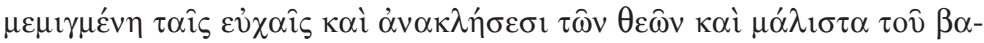

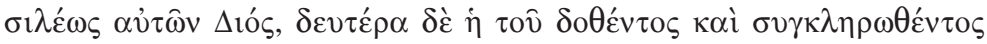

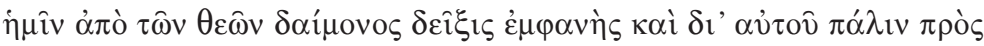

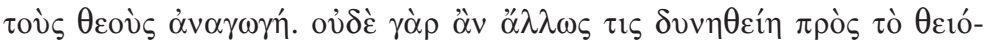

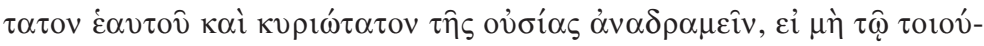

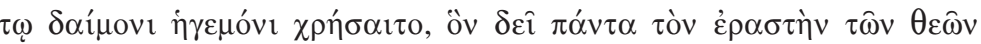

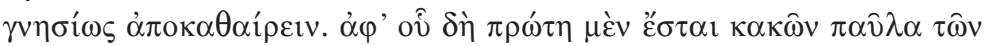

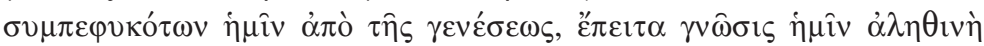

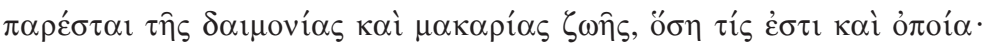

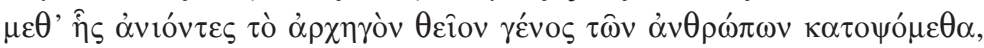

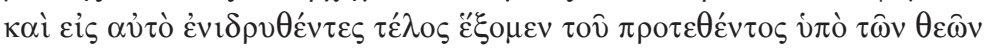

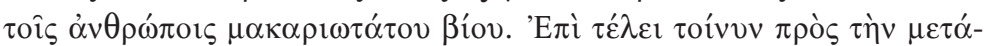

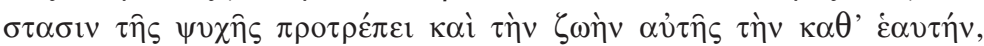

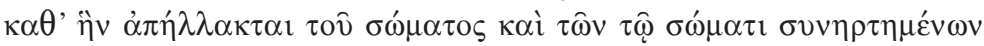

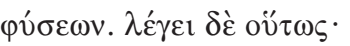

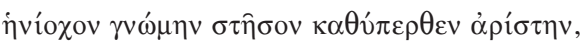

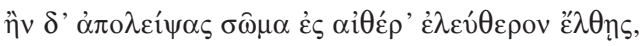

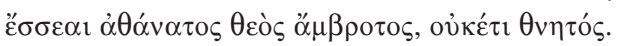

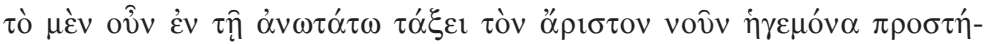

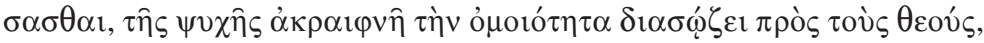

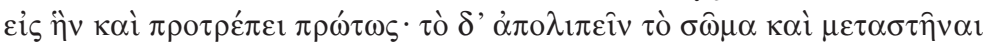

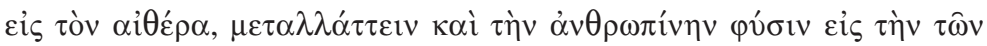

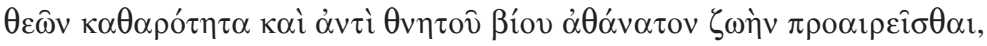

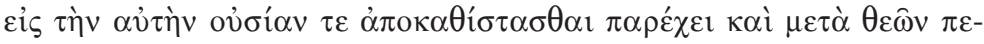

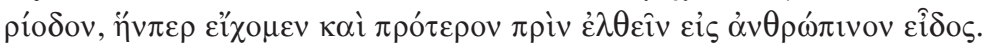

palabra, por extensión, también puede designar "la suerte" o "el destino" (cfr. supra, n. 43; véase también Ioannides). A propósito de los démones en Jámblico, cfr. Zeller, pp. 21-23; Dillon, 1973, pp. 48-52.

${ }^{52}$ Acerca de la relación de los hombres y los dioses, cfr. Pépin, pp. 1-51; Des Places, 1964

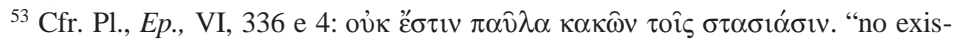
te cesación de los males para quienes pelean", cfr. Id., $R$., V, 473 d 5; VI, 501 e 4.

${ }^{54}$ La metáfora del cochero pertenecía al antiguo pitagorismo, lo mismo que el célebre "mito de la auriga" de Platón (Phdr., 246-248). La inteligencia ( $\gamma v \omega ́ \mu \eta)$ conduce un cuerpo sutil y etéreo que el alma ha recibido conforme a su ser. En el 
Mas tú no temas, pues origen divino tienen los hombres. ${ }^{52}$

En estos versos se halla, primero, una excelente invitación a la felicidad divina; dicha invitación está mezclada con súplicas e invocaciones a los dioses, sobre todo, a Zeus, el rey de ellos; en segundo lugar, se habla acerca del alma, que los dioses nos asignaron y nos dieron, y, a través de ella, de un nuevo ascenso hacia los dioses. En efecto, sólo puede uno remontarse hacia lo más divino de sí mismo y hacia lo más valioso de su esencia, cuando uno se deja guiar por el alma, a la cual es necesario que todo amante de los dioses purifique verdaderamente. A partir de entonces, habrá un primer desplazamiento de los males ${ }^{53}$ inherentes a nosotros desde el nacimiento, después se nos hará presente el verdadero conocimiento de la grandeza y de la esencia de la vida dichosa y feliz. Elevándonos por medio de este conocimiento, observaremos que el origen de los hombres es primordialmente divino y, colocados en ese rango, disfrutaremos la vida más dichosa, esa que los dioses han concedido a los hombres.

Al final, el poema exhorta hacia la transformación del alma y hacia su existencia de acuerdo con su propia naturaleza, que se aparta del cuerpo y de sus instintos inherentes. Dice así:

Las mejores ideas, como aurigas, en alto coloca;

si abandonando el cuerpo, hacia el libre éter marcharas, serás un dios inmortal, incorruptible, ya no mortal..$^{54}$

El colocar como guía, en el rango más elevado, al grandioso intelecto, preserva pura la semejanza del alma con los dioses, y con igual prioridad nos exhorta a dicha semejanza. El abandonar el cuerpo y trasladarse hacia el éter, el intercambiar también la naturaleza humana por la pureza de los dioses y el preferir, en vez de la vida mortal, la existencia inmortal, permite regresar a la misma esencia y a la órbita de los dioses, las cuales teníamos antes de tomar forma humana.

éter, el alma por fin ha abandonado el mundo sublunar y el cuerpo que la aprisionaba, y recobra su naturaleza inmortal y divina, librada ya del ciclo del nacimiento, es decir, de la metempsicosis. El parentesco del alma humana con lo divino, tema de la sentencia anterior, es la condición necesaria de su asimilación, cfr. Pépin, pp. 8-11. 


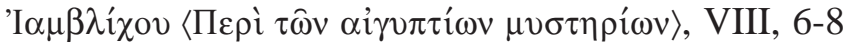

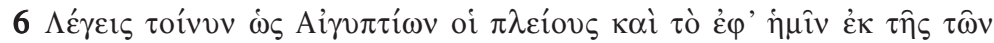

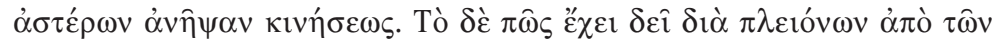

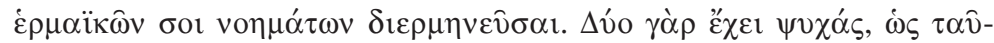

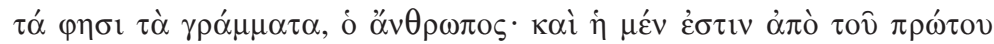

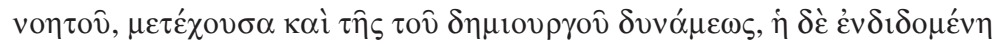

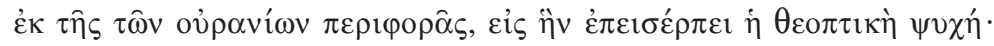

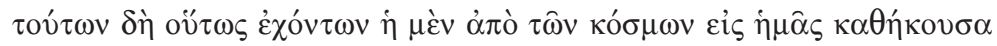

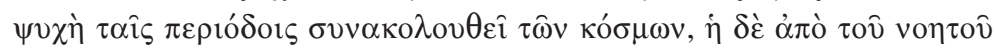

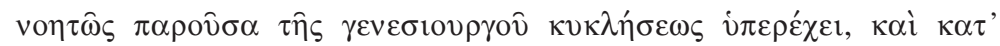

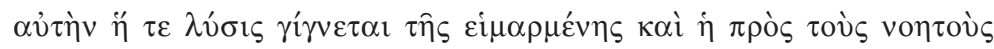

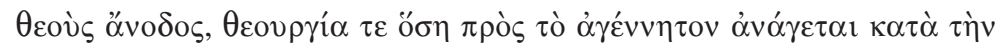

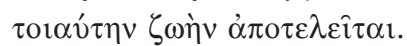

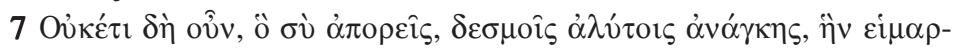

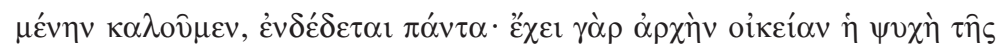

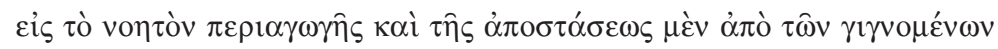

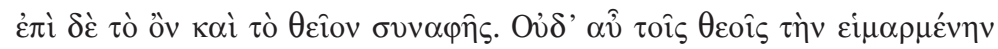

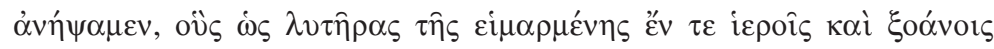

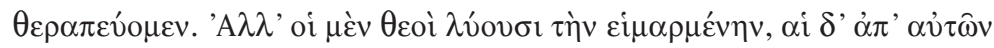

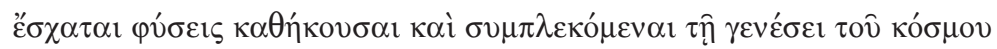

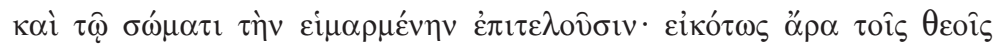

\footnotetext{
${ }^{55}$ Numenio, entre otros, postuló dos almas y no, como era común en el platonismo, tres o dos partes del alma, una racional y otra irracional; cfr. Numenius, fr. 44,

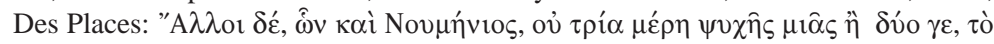

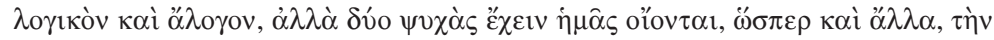

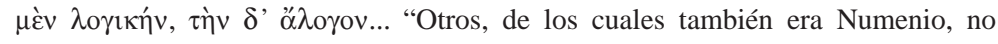
piensan que nosotros tengamos tres partes de un alma única, o al menos dos, la parte racional y la irracional, sino dos almas, como también otras cosas, el alma racional y la irracional”. Psello refería a Platón una doctrina de dos almas, extraída de las enseñanzas de Hermes y de Bitys (cfr. Clarke, n. ad loc.), una que emana del demiurgo, y otra, de la esfera celeste y, por ello, sujeta al destino; esta última, bajo cierta perspectiva podría ser identificada con el "vehículo" que el alma recibe en su descenso. El objetivo es, precisamente, liberar al hombre del destino, por lo cual el ser humano, i. e., su alma, debe tener un estatus superior al de la naturaleza, en oposición a la doctrina que Porfirio cree ser la de los egipcios, y que en alguna medida compartirían los estoicos.
} 
Jámblico, <Acerca de los misterios egipcios>, VIII, 6-8

6 Dices, además, que la mayoría de los egipcios a lo que depende de nosotros también lo enlazan al movimiento de los astros. Es preciso explicarte, mediante diversas nociones que vienen de los herméticos, cómo es esto. En efecto, el hombre, como estos escritos afirman, tiene dos almas. ${ }^{55}$ Una es la que proviene a partir del primer inteligible, que participa también de la potencia del demiurgo; la otra es la que fue entregada a partir de la revolución de los cuerpos celestes, hacia la cual se desliza el alma que ve a dios. Siendo estas cosas de esta manera, el alma que desciende hacia nosotros desde los cos$\operatorname{mos}^{56}$ acompaña los periodos de los cosmos; la que viene de lo inteligible, estando presente inteligiblemente, supera a la circulación generativa, y de acuerdo con ella se da la liberación del destino y el retorno a los dioses inteligibles, y cuanta teúrgia se eleva hacia lo inengendrado, se lleva a cabo según tal vida.

7 Entonces, en cuanto a lo que tú estás en duda, ya no están atadas todas las cosas por lazos indisolubles de necesidad, a la cual llamamos destino, pues el alma tiene un principio propio de la rotación hacia lo inteligible, y de la separación de lo que deviene, y del contacto con lo que es y con lo divino. A su vez, tampoco atamos el destino con los dioses, a los cuales veneramos como libertadores del destino en templos y esculturas. Sin embargo, los dioses liberan el destino; y las últimas naturalezas que desde ellos descienden y se entretejen con la generación del cosmos y con el cuerpo, llevan a cabo el destino. ${ }^{57}$ Por tanto, naturalmente a los

\footnotetext{
${ }^{56}$ La filosofía griega tuvo varias opiniones respecto a la unicidad del cosmos. La opinión platónica, según la cual el cosmos es uno, fue la predominante. Para los estoicos, el cosmos tenía recurrentes conflagraciones, tras las cuales se volvía a reconstituir, de manera que podía hablarse de diferentes "cosmos" sucesivos; en cambio, el Epicureísmo distinguió entre el universo único, el conjunto de todo lo que existe, y los distintos "cosmos", i. e., "mundos", que podría haber simultáneamente en él. Aquí, en este pasaje, el plural parece obedecer a la doctrina caldea donde "los cosmos" parecen designar cada uno de los niveles celestes, cuyos límites señalan las órbitas de cada uno de los planetas.

${ }^{57}$ En Iambl., Myst., V, 9, se hablará también de "las potencias terminales de los dioses", y de "potencias cósmicas o terrestres de démones o de dioses".
} 


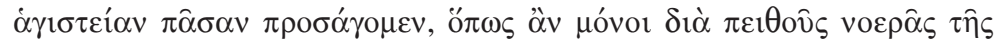

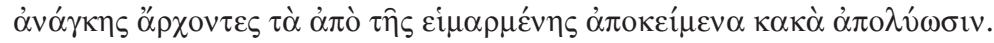

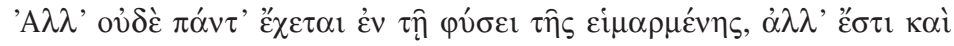

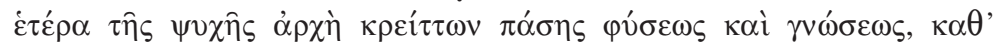

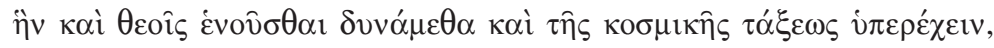

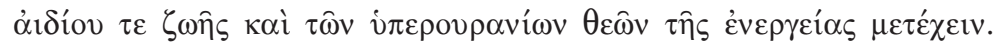

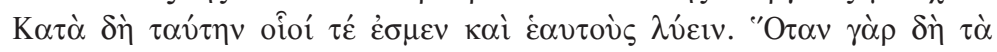

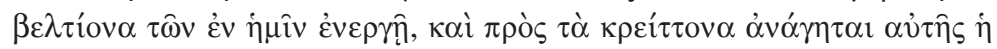

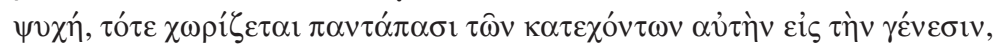

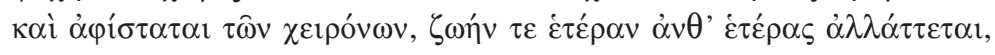

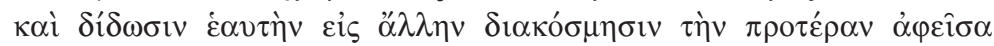
$\pi \alpha v \tau \varepsilon \lambda \hat{\omega} \varsigma$.

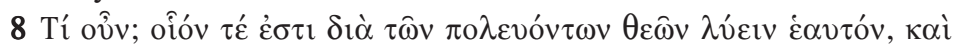

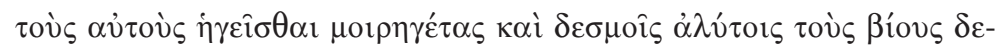

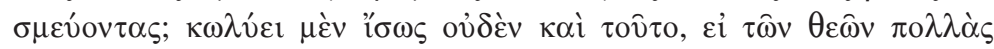

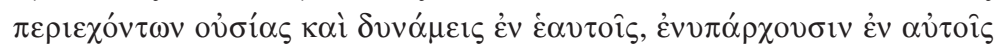

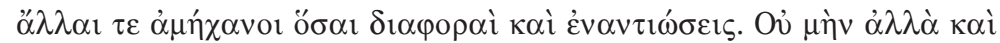

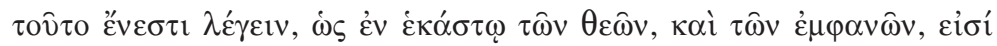

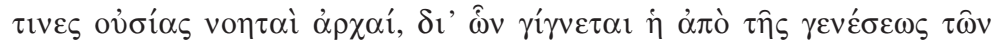

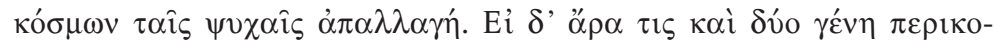

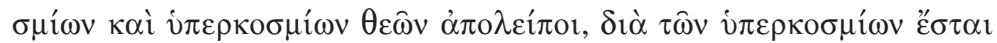

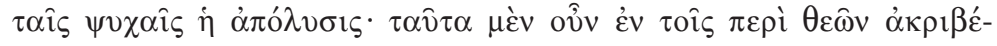

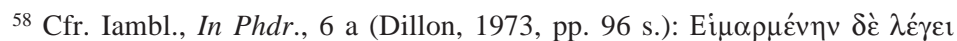

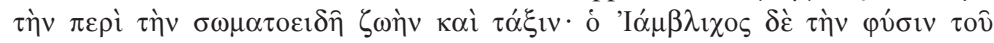
$\pi \alpha v \tau$ ò $\varepsilon^{i} \mu \alpha \rho \mu \varepsilon ́ v \eta \nu \kappa \alpha \lambda \varepsilon \hat{i}$. "dice (sc. Platón) que es destino el que tiene que ver con la vida y con el orden corporiformes. Y Jámblico llama destino a la naturaleza del todo". Ver también el comentario de Dillon, ad loc. ib., pp. 254 s. Ver igualmente Iambl., Myst., X, 5.

${ }^{59}$ Según Jámblico, el alma no puede liberarse a sí misma, sino que necesita la ayuda divina, por eso aquí el genitivo debe ser leído como genitivo objetivo, cfr. Stäcker, p. 146.

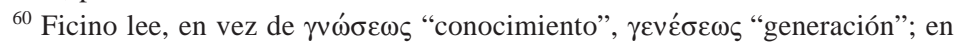
ese caso se trataría si no de un pleonasmo, al menos de una endíadis. Clarke et al. consideran "conocimiento" como fuera de contexto, y prefieren, en contra de Des Places, la lectura de Ficino adoptada también por Taylor.

${ }^{61}$ Debe entenderse esta frase con restricciones; ver supra, n. 59, e infra, nts. 62 y 63; cfr. Stäcker, pp. 147 s.

${ }^{62}$ Según Stäcker (p. 147), en consonancia con el pensamiento de Jámblico, aquí no debería entenderse "lo mejor de nosotros", es decir, el genitivo no debe leerse como partitivo, sino como segundo término de comparación. 
dioses ofrecemos toda ceremonia, para que, como arcontes únicos de la necesidad, mediante persuasión intelectual, disuelvan los males que se dan por destino. ${ }^{58}$

Pero ni siquiera todo lo que está en la naturaleza se atiene al destino, sino existe también otro principio sobre el alma, ${ }^{59}$ superior a toda naturaleza y conocimiento ${ }^{60}$ según el cual también podemos unirnos a los dioses y superar el orden cósmico, y participar de la vida eterna y de la actividad de los dioses supracelestes. De acuerdo con este principio somos capaces también de liberarnos a nosotros mismos. ${ }^{61}$ En efecto, cuando actúan los mejores que lo que está en nosotros, ${ }^{62}$ y el alma se eleva ${ }^{63}$ hacia lo superior a ella, entonces se separa absolutamente de lo que la retiene en la generación, y se separa de lo inferior, toma a cambio una vida en vez de otra, y se da a sí misma a otra distribución dejando completamente la primera.

8 ¿Qué, entonces? ¿Es posible, mediante los dioses que giran, liberarse a sí mismo, y que se considere a los mismos como dominadores de la suerte ${ }^{64}$ y que con vínculos indisolubles atan las vidas? Quizá nada impide tampoco esto, si, rodeando los dioses en sí mismos muchas esencias y potencias, tienen en ellos otras distinciones y contradicciones inmensas. Sin embargo, también es posible decir esto: que en cada uno de los dioses, incluso de los manifiestos, hay algunos principios inteligibles de esencia, a través de los cuales se produce para las almas la separación de la generación de los cosmos. Por tanto, incluso si alguno dejara dos géneros de dioses cósmicos e hipercósmicos, mediante los hipercósmicos será posible para las almas la disolución. ${ }^{65}$ Estas cosas se dicen más exactamente en los tratados acerca de los dioses: ${ }^{66}$ quiénes son los

63 Es verdad que la forma óvó $\gamma\rceil \alpha \imath$ puede leerse como voz media, pero también como voz pasiva, i. e., "es elevada" (cfr. Stäcker, p. 147); más abajo se hablará de los "dioses que elevan", cfr. infra, n. 67.

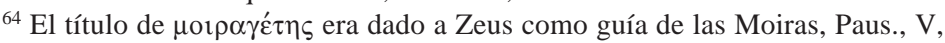
15, 5; VIII, 37, 1), y a veces también a Apolo (Paus., X, 24, 4); Apolonio de Rodas afirma que de entre los Dáctilos ideos sólo Ticias y Cileno merecieron ese apelativo (I, 1126-1129); Alcifrón (Alciphr., I, 20) se lo da a los démones, cfr. LSJ, s. v.

${ }^{65}$ Es decir, la disolución de los vínculos que las atan al destino.

66 Se ha querido ver aquí una referencia de Jámblico a su propia obra con ese título; en ese caso habría olvidado su propio pseudónimo; puede ser, sin embargo, que se refiera a algunos de los tratados herméticos que se hayan ocupado de esa temática, y que al mismo tiempo sea una velada alusión a su obra. 


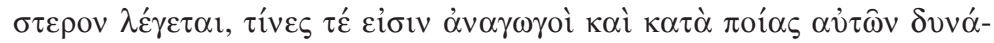

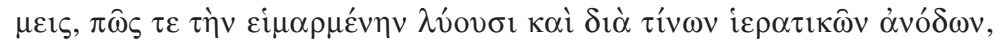

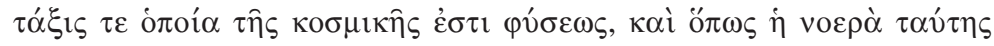

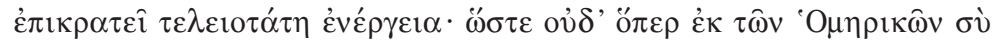

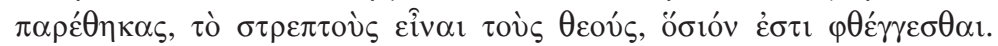

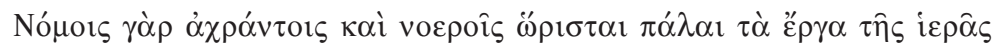

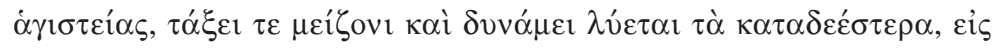

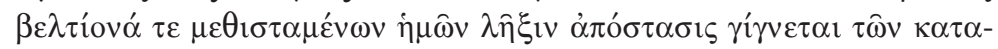

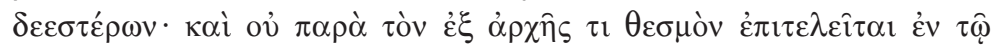

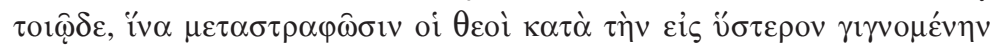

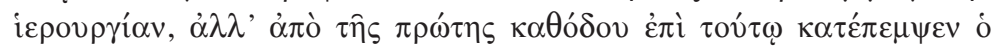

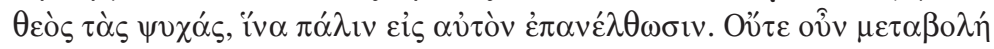

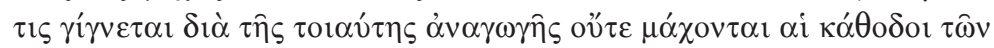

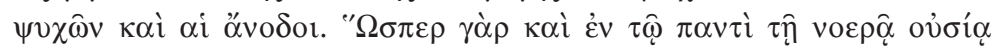

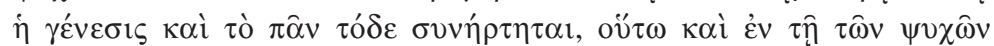

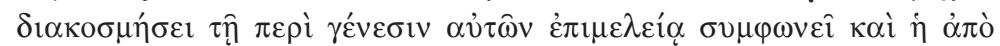

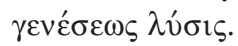

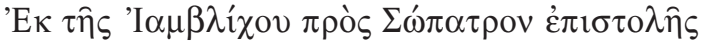 \\ (Stob., I, 81)}

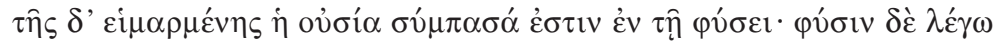

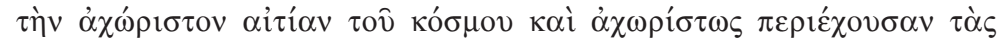

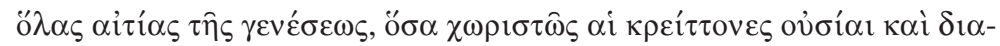

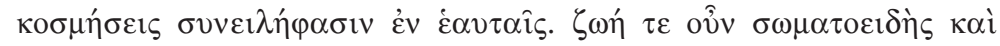

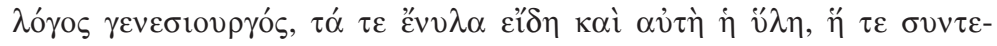

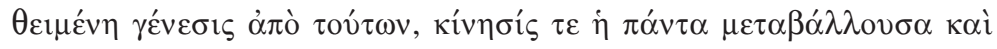

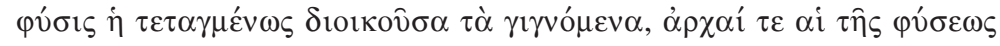

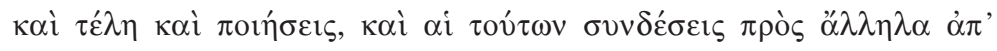

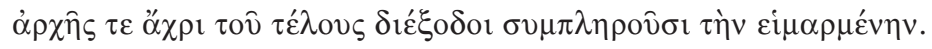

${ }^{67}$ Se trata de los $\theta \varepsilon o i ̀ ~ \alpha ́ v \alpha \gamma \omega \gamma o i ́$, a los cuales Proclo se refiere en Procl., In R., 1, 90; 2, 52; In Ti., 1, 154.

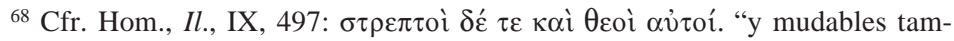
bién los dioses mismos". Las palabras son de Fénix queriendo convencer a Aquiles de regresar al combate y de olvidar el agravio de Agamenón.

${ }^{69}$ Sc. el llamado demiurgo. 
que elevan ${ }^{67}$ y de acuerdo con cuáles potencias, cómo liberan del destino y mediante cuáles ascensiones sagradas, cuál es el orden de la naturaleza cósmica y cómo la más perfecta actividad intelectual domina a ésta; de manera que ni lo que tú aportaste de los versos homéricos, el que los dioses son mudables, ${ }^{68}$ es santo decirlo. En efecto, desde antiguo se determinan por leyes inmaculadas e intelectuales las obras de la ceremonia sagrada, y por un orden y una potencia mayores se libera lo inferior, y trasladándonos hacia una mejor suerte se produce la separación de lo inferior. Y nada se lleva a cabo contra la institución del principio en tal situación, para que los dioses cambien de acuerdo con la acción sagrada posterior, sino desde el primer descenso, dios ${ }^{69}$ envió abajo a las almas para esto, para que de nuevo regresaran hacia él. Por tanto, ni se produce cambio alguno mediante tal ascensión ni combaten los descensos y los ascensos de las almas. ${ }^{70}$ En efecto, como también en el universo, la generación y este universo se entrelazan con la esencia intelectual, así, también en la distribución de las almas, la liberación de la generación, concuerda con el cuidado que se tiene de ellas ${ }^{71}$ en su generación.

\section{De la epístola a Sopatro \\ (Stob., I, 81)}

La esencia del destino está toda en la naturaleza. Y digo naturaleza a la causa inseparable del cosmos y que inseparablemente rodea las causas enteras de la generación; todo cuanto, separadamente, las esencias y disposiciones superiores comprenden en sí mismas. Por tanto, es vida corporiforme y razón que incide en la generación, las formas implicadas en la materia y la materia misma, la generación compuesta a partir de estos factores, y el movimiento que cambia todo, y la naturaleza que administra ordenadamente lo que se genera, y los principios y los fines y las producciones de la naturaleza, y las vinculaciones de éstos entre ellos, y sus travesías desde el principio hasta el final, cumplen el destino.

${ }^{70}$ A propósito de los distintos fines por los cuales desciende el alma a un cuerpo, cfr. Iambl., de An., 26-30, Finamore-Dillon.

${ }^{71}$ Genitivo objetivo. 


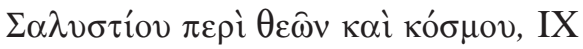

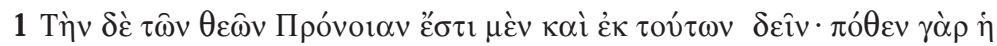

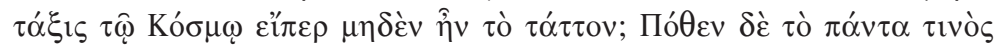

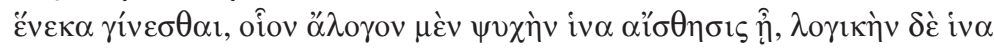
$\kappa о \sigma \mu 8 \tau \alpha \iota \imath \dot{\eta} \gamma \hat{\eta} ;$

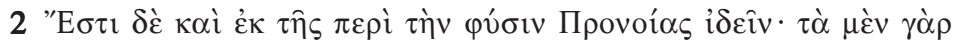

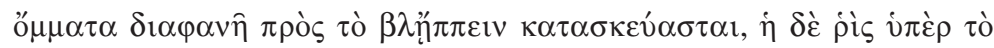

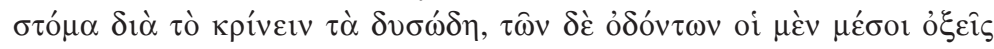

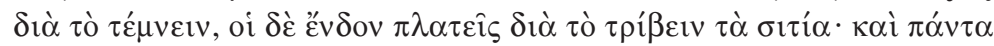

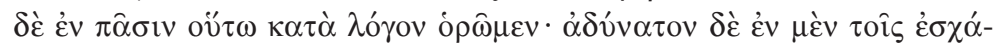

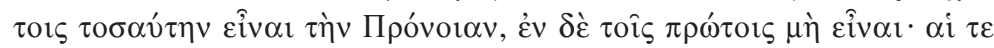

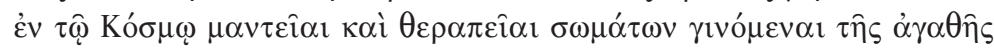

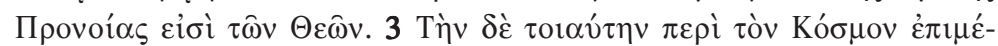

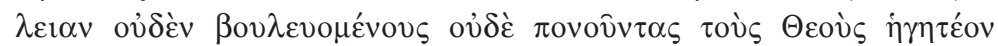

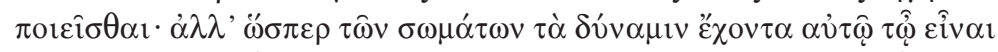

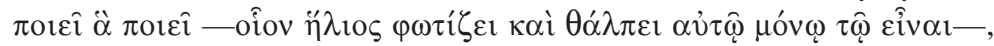

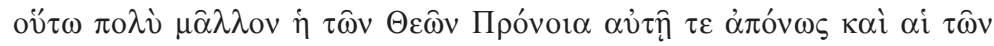

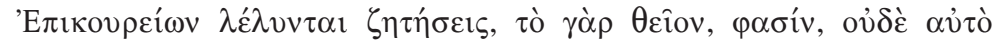

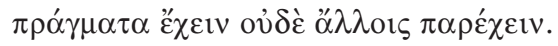

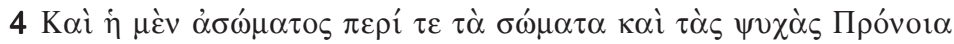

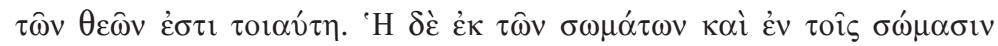

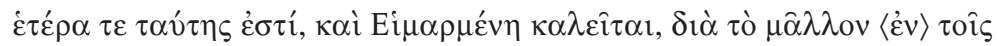

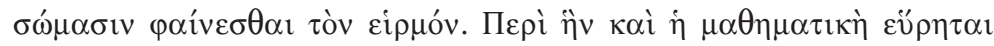

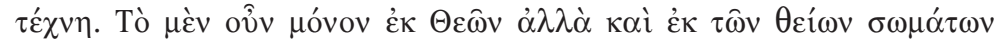

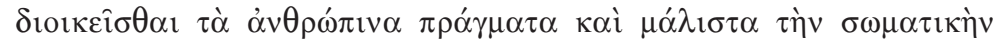

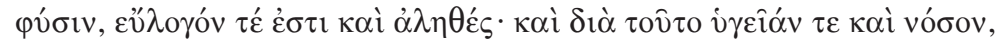

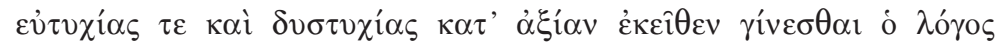

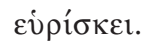

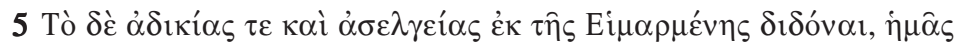

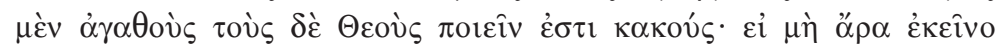

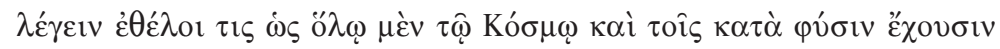

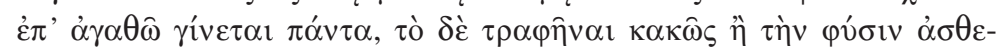

\footnotetext{
${ }^{72}$ Explicación "etimológica", mejor dicho, sólo "fonética", del destino: ei $\mu \alpha \rho$ -

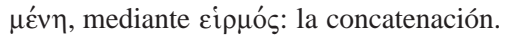

${ }^{73}$ Cfr. Iambl., Myst., I, 18 (ver nota siguiente), e ib., IV, 4-6.
} 


\section{Salustio, Acerca de los dioses y del mundo, IX}

1 A la providencia de los dioses es posible verla también a partir de esto: ¿de dónde, pues, el mundo tiene un orden, si lo que ordena fuera nada? ¿De dónde el que todo se genere para algo, por ejemplo, alma irracional, para que haya sensación; racional, para que la tierra esté ordenada?

2 Es posible también verla a partir de la providencia sobre la naturaleza; en efecto, los ojos han sido dispuestos diáfanos para mirar; la nariz sobre la boca para discernir las cosas fétidas; de los dientes, los medios son agudos, para cortar; los interiores, anchos, para moler los alimentos; y vemos que todas las cosas en todo son así razonablemente. Es imposible que la providencia sea tanta en las cosas últimas, pero que no exista en las primeras. Los oráculos y cuidados que se generan de los cuerpos son propios de la buena providencia de los dioses. 3 Hay que considerar que los dioses emprenden tal cuidado sobre el mundo nada deliberando ni fatigándose, sino así como de los cuerpos el que tiene una facultad hace lo que hace por el solo existir — como el sol ilumina y calienta por el solo existir- así mucho más la providencia de los dioses se genera por ella misma sin fatiga por el bien de los que gozan de su providencia, de manera que incluso las inquisiciones de los epicúreos están solucionadas, pues lo divino, afirman, ni tiene dificultades ni las proporcionan a otros.

4 También la providencia incorpórea de los dioses sobre los cuerpos y las almas es así. Pero la que surge de los cuerpos y reside en los cuerpos es distinta a ésta, y se llama destino, porque la concatenación ${ }^{72}$ aparece más en los cuerpos. Acerca de ésta incluso se ha inventado el arte matemático. Entonces, que no sólo a partir de los dioses sino también a partir de los cuerpos divinos se administran los asuntos humanos, y sobre todo la naturaleza corpórea, es razonable y verdadero. De ahí que, también por esto, la razón encuentra que según el mérito se generan salud y enfermedad, éxitos y fracasos.

5 El dar a partir del destino injusticias y desenfrenos es hacernos buenos a nosotros, pero malos a los dioses, si no quisiera alguno decir esto: que todo se genera para el bien ${ }^{73}$ del mundo entero y de los seres que existen de acuerdo con la naturaleza, pero el ser mal 


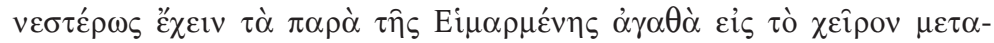

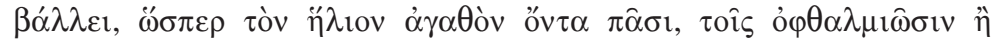

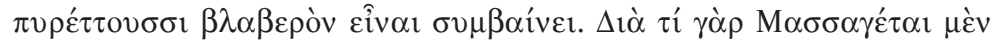

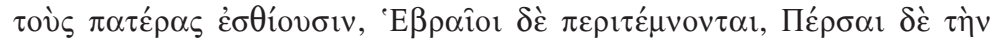

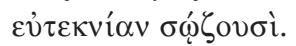

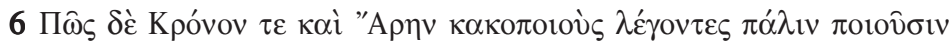

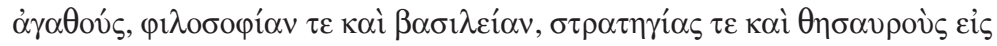

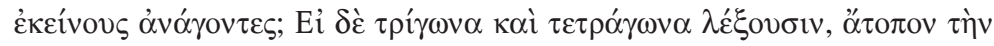

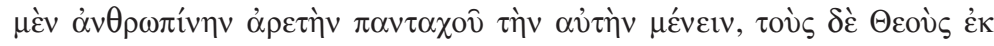

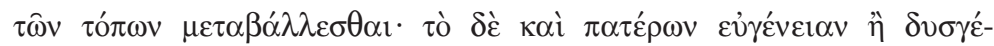

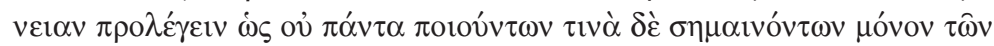

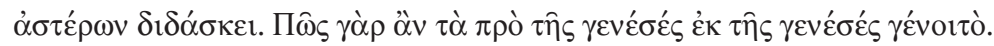

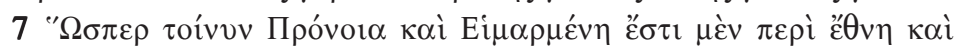

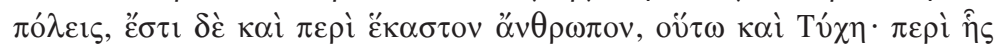

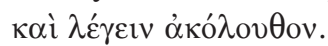

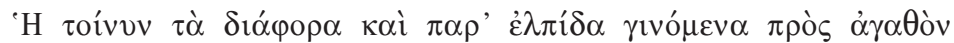

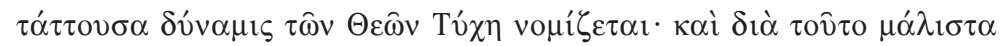

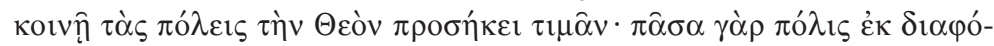

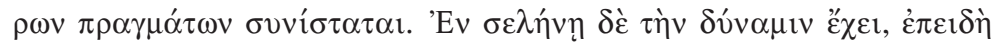

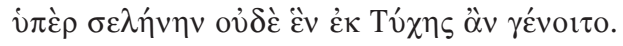

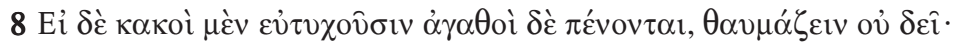

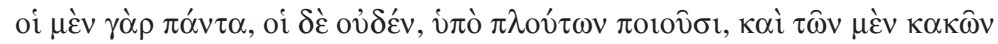

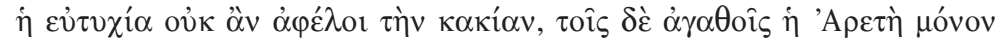

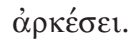

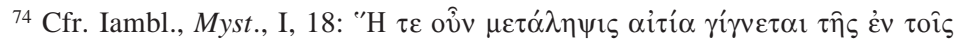

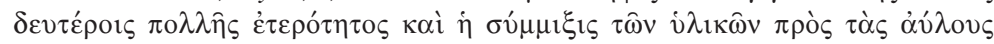

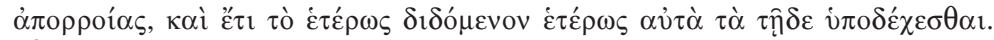

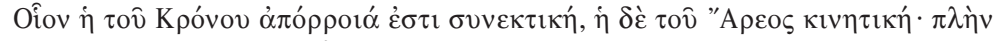

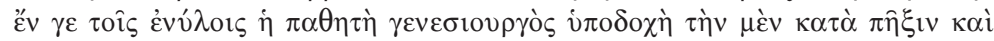

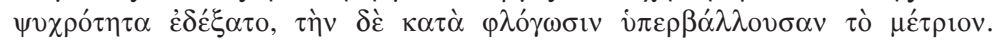

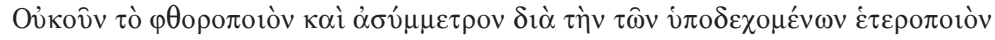

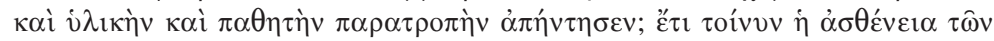

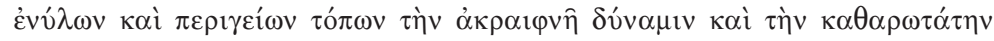

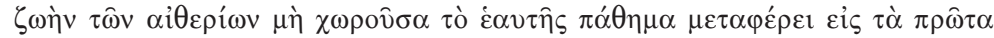

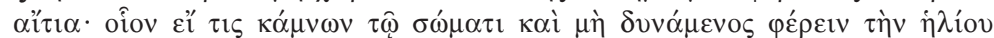

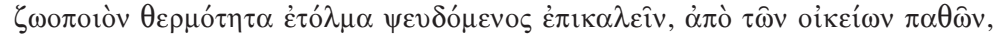

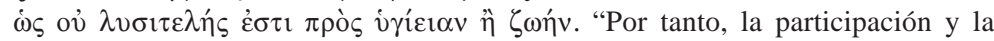
mezcla de los seres materiales con las emanaciones inmateriales, y además el hecho de que lo concedido de una manera los seres de aquí lo reciben de otra, se hacen causa de la mucha alteridad en los seres secundarios. Como la emanación 
educado o ser muy débil de naturaleza cambia los bienes recibidos de parte del destino hacia lo menos bueno, así como ocurre que el sol, aunque es bueno para todos, es nocivo para los que padecen oftalmía o a los que tienen fiebre. ${ }^{74}$ ¿Por qué, pues, los masagetas comen a sus padres, y los hebreos se circuncidan, y los persas observan la abundancia de hijos?

6 ¿Cómo diciendo que Cronos y Ares son malhechores, ${ }^{75}$ de nuevo los hacen buenos, refiriendo a ellos filosofía y reino, jefatura del ejército y tesoros? Pero si cuentan triángulos o cuadrángulos, es absurdo que la virtud humana permanezca la misma en todas partes, y que los dioses se cambien de sus lugares. Incluso predecir el origen noble u obscuro de los padres enseña que los astros no hacen todo, sino sólo muestran algunos indicios. ¿Cómo, pues, se habrían generado a partir de la generación lo anterior a la generación?

7 Entonces, así como providencia y destino existen sobre pueblos y ciudades, y existen también sobre cada hombre, así también, suerte, acerca de la cual también es consecuente hablar.

Así pues, se considera suerte a la potencia de los dioses que ordena los cambios de fortuna y las cosas que suceden contra lo esperado hacia el bien. Y por esto, sobre todo conviene que las ciudades honren oficialmente a la diosa, pues toda ciudad se compone a partir de asuntos que cambian la fortuna. En la luna tiene su potencia, ya que sobre la luna ni una sola cosa se podría generar a partir de la suerte.

$8 \mathrm{Si}$ los malos tienen éxito, y los buenos, penurias, no es preciso admirarse, pues unos, todo, otros, nada hacen por riquezas, y el éxito de los malos no anularía la maldad, pero a los buenos sólo bastará la virtud.

de Cronos es cohesiva, la de Ares, agitadora; pero en los seres materiales el receptáculo pasible generador recibió a una de acuerdo con el congelamiento y la frialdad, a la otra de acuerdo con una calefacción que excede lo adecuado. ¿Acaso no, lo causante de destrucción y desproporcionado acaeció por la desviación diferenciante material y pasible de los seres que la admiten? Además, la debilidad de los lugares materiales y terrestres, no haciendo sitio a la potencia no mezclada y a la vida más pura, traslada su propia afección a los causantes primeros; como si alguno estando enfermo de su cuerpo y no pudiendo soportar el calor vivificante del sol, se atreviera, mintiendo, a acusarlo, por las propias pasiones, de que no es útil para la salud o la vida".

${ }^{75}$ Dioses, Cronos y Ares, que tal vez sin casualidad cita Jámblico en el mismo fragmento de la nota anterior. 
JOSÉ MOLINA

\section{BIBLIOGRAFÍA}

Jámblico: ediciones y traducciones

I. Commentaria in Platonem et Aristotelem

DalsgaArd Larsen, Bent, Jamblique de Chalcis: Éxégète et philosophe, 2 vol. (Appendice: Testimonia et fragmenta exegetica), Aarhus, Universitetsforlaget, 1972.

Dillon, John, Iamblichi Chalcidensis. In Platonis Dialogos Commentariorum Fragmenta, Leiden, E. J. Brill (Philosophia Antiqua, XXIII), 1973.

II. Colección de las doctrinas pitagóricas

a) De vita pythagorica

Brisson, Luc, et A. Ph. Segonds, Jamblique, Vie de Pythagore, Paris, "Les Belles Lettres" (La roue à livres), 1996, LXXXIX + 240 págs. Deubner, Ludovicus, Iamblichi De vita pythagorica liber (addendis et corrigendis adiunctis curavit Udalricus Klein), Stuttgart, Teubner (Bibliotheca Scriptorum Graecorum et Romanorum Teubneriana), 1974 (1937), XLIV + 157 págs.

Dillon, John, and J. Hershbell, Iamblichus: On the Pythagorean Way of Life, text, transl. and nts., Atlanta, Scholars Press (Society of Biblical Literature, Texts and Translations, 29; Graeco-Roman Religion series, 11), 1991.

Periago Lorente, Miguel, Jámblico, Vida pitagórica. Protréptico, intr., trad. y nts., Madrid, Gredos (Biblioteca Clásica Gredos, 314), 2003, 314 págs.

Ramos JuRado, Enrique A., Jámblico, Vida pitagórica, Madrid, Etnos, 1991, 169 págs.

Von AlBRECHT, Michael, et al., Jamblich. ПЕPI TOY ПYӨАГOPEIOY BIOY / Pythagoras: Legende-Lehre-Lebensgestaltung, Eingeleitet, übersetzt und mit interpretierenden Essays versehen von Michael von Albrecht, John Dillon, Martin George, Michael Lurje, David S. du Toit, Darmstadt, Wissenschaftliche Buchgesellschaft (Scripta Antiquitatis Posterioris ad Ethicam REligionemque pertinentia [SAPERE], IV), 2002. 


\section{b) Protepticus in philosophiam}

Des Places, Édouard, S. J., Jamblique, Protreptique, Paris, "Les Belles Lettres", 1989, 172 págs.

Johnson, Thomas Moore, Iamblichus, The Exhortation to Philosophy. Including the letters of Iamblichus and Proclus' commentary on the Chaldean Oracles (with a foreword by Joscelyn Godwin. Edited by Stephen Neuville), Grand Rapids, Phanes Press, 1988, 128 págs.

Periago Lorente, Miguel, Jámblico, Vida pitagórica. Protréptico, intr., trad. y nts., Madrid, Gredos (Biblioteca Clásica Gredos, 314), 2003, 314 págs.

Pistelli, Hermenegildus, Protrepticus, Stuttgart, Teubner (Bibliotheca Scriptorum Graecorum et Romanorum Teubneriana), 1967 (1888), XIV + 170 págs.

SchönBerger, O., Iamblichos, Aufruf zur Philosophie (Erste deutsche Gesamtübersetzung. Mit zweisprachiger Ausgabe von Ciceros Hortensius von O. Schönberger), Würzburg, Königshausen + Neumann, 1984, 110 págs.

c) De communi mathematica scientia liber

FeSTA, Nicolaus, Iamblichi De communi mathematica scientia liber (reimpr. con supl. de U. Klein), Stuttgart, Teubner (Bibliotheca Scriptorum Graecorum et Romanorum Teubneriana), 1975 (1891).

\section{De Mysteriis}

Clarke, Emma C., John M. Dillon y Jackson P. Herschbell, Iamblichus, On the Mysteries, Atlanta, Society of Biblical Literature (Writings from the Greco-Roman World, 4), 2003.

Des Places, Édouard, S. J., Jamblique, Les mystères d'Égypte, Paris, "Les Belles Lettres", 1966.

—, Jamblique. Les mystères d'Égypte, Paris, "Les Belles Lettres" (Aux sources de la tradition), 1993.

Hopfner, Theodor, Jamblichus. Über die Geheimlehren, Hildesheim, Georg Olms, 1987 (Leipzig, Theosophisches Verlagshaus, 1922).

Moreschini, Claudio, Giamblico. I misteri degli egiziani, Milano, Biblioteca universale Rizzoli (Classici greci e latini, 1448), 2003.

Ramos Jurado, Enrique A., Jámblico. Sobre los misterios egipcios, Madrid, Gredos (Biblioteca Clásica Gredos, 242), 1997. 
Sodano, Angelo Raffaele, Giamblico. I Misteri Egiziani. Abammone, Lettera a Porfirio, Milano, Rusconi, 1984.

TAYLOR, Thomas, Iamblichus. On the Mysteries of the Egyptians, Chaldeans and Assyrians, New Bio-bibliographical Glossary, San Diego, Wizards Bookshelf (Secret Doctrine Reference Series), 1997.

IV. De anima

Festugière, A.-J., O. P., La révélation d'Hermes Trimégiste. III. Les doctrines de l'ame (suivi de JAMBLIQUE, Traité de l'âme, pp. III, 177-264, traduction et commentaire. Porphyre, De l'animation de l'embryon). IV. Le dieu enconnu et la gnose, Paris, "Les Belles Lettres" (Collection d'études anciennes. Serie grecque 77), 1990, (III) XIV + $314+$ (IV) XI + 319 págs.

Finamore, F., y John M. Dillon, Iamblichus, De Anima, Leiden, Brill, 2002.

Wachsmuth, C., and O. Hense (eds.), Stobaei Anthologii libri duo priores qui inscribi solent Eclogae physicae et ethicae [I, 362, 23-458-23 = Iamblichus, De Anima], 5 vols., Berlin, Weidmann, 1884-1923.

\section{Bibliografía general}

Aulo Gelio, Noches áticas, II (Libros $V$-X), intr., trad., nts. e índ. on. Amparo Gaos Schmidt, México, Universidad Nacional Autónoma de México (Bibliotheca Scriptorum Graecorum et Romanorum Mexicana), 2002.

Blumenthal, Henry J., et E. G. Clark (eds.), The divine Iamblichus, London, Bristol Classical Press, 1993.

Bruns, I. (ed.), Alexandri Aphrodisiensis De fato ad imperatores, Supplementum Aristotelicum ap. Commentaria in Aristotelem Graeca, II, 2, Berlin, G. Reimer, 1892.

Corpus Hermeticum, 4 vols., ed. y trad. A. D. Nock y A.-J. Festugière, Paris, "Les Belles Lettres", 1972-1973.

Des Places, Édouard, Syngeneia. La parenté de l'homme avec dieu, d' Homére à la patristique, Paris, Librairie C. Klincksieck (Études et Commentaires, LI), 1964b.

Dillon, John, "Tradition and personal achievement in the philosophy of Plotinus", Journal of Roman Studies, 50, 1960, pp. 1-7.

Festugière, A.-J., Les Trois "Protreptiques" de Platon. Euthydème, Phédon, Epinomis, Paris, Libraire Philosophique J. Vrin (Bibliothèque d'histoire de la philosophie), 1973. 
Finamore, John F., Iamblichus and The Theory of the Vehicle of the Soul, Chico (California), Scholars Press, 1985.

IoAnNides, Klitos, "Les genies intermédiaires en Grèce", Zenon II, Lefkosia, Publ. de la Société Philosophique de Chipre, 1981, pp. 91-95.

Juvénal, Satires, ed. y trad. Pierre de Labriolle y François Villeneuve, Paris, "Les Belles Lettres", 1974.

LidDEll, Henry George, and Robert ScotT, A Greek-English Lexicon, Oxford, Oxford Clarendon Press, 1968 (9a. ed.).

Merlan, Ph., From Platonism to Neoplatonism, The Hague, Martinus Nijhoff, 1953.

Nasemann, Beate, Theurgie und Philosophie in Jamblichs De Mysteriis, Stuttgart, B. G. Teubner, 1991.

NumÉnius, Fragments, ed. y trad. Édouard des Places, Paris, "Les Belles Lettres", 1973.

O’ Meara, Dominic J., "La question de l'être et du non être des objects mathématiques chez Plotin et Jamblique", Revue de théologie et de philosophie, 122, 1990, pp. 405-416.

-, Pythagoras revived. Mathematics and Philosophy in Late Antiquity, New York, Oxford University Press, 1992 (third impression).

Oracles Chaldaïques. Avec un choix de Commentaires Anciens, ed. y trad. Édouard des Places, Paris, "Les Belles Lettres", 1971.

Pausanias, Description of Greece, 5 vols., tr. W. H. S. Jones, Cambridge, Ma., Harvard University Press / London, William Heineman (Loeb Classical Library), 1969-1971.

PépIN, Jean, Idées grecques sur l'homme et sur Dieu, Paris, "Les Belles Lettres", 1971.

Platonis Opera, 5 vols. Oxonii, E Typographeo Clarendoniano, 19001915.

Plotin, Ennéades, 6 tomos en 7 vols., ed. y trad. Émile Bréhier, Paris, "Les Belles Lettres", 1923-1938.

Plutarco, Acerca del destino, intr., trad., nts. e índ. Pedro C. Tapia Zúñiga y Martha E. Bojórquez Martínez, México, Universidad Nacional Autónoma de México (Bibliotheca Scriptorum Graecorum et Romanorum Mexicana), 1996.

Proclus, Trois Études sur la Providence, II: Providence, fatalité, liberté, ed. y trad. Daniel Isaac, Paris, "Les Belles Lettres", 1979.

Rist, John M., "Prohairesis: Proclus, Plotinus et alii", Entretiens Hardt pour l'étude de l'antiquité classique publiés par Olivier Reverdin, Tome XXI. De Jamblique à Proclus (Entretiens préparés et présidés par Heinrich Dörrie), Genève-Vandeouvres, Fondation Hardt, 1975, pp. 108-117. 
Saloustios, Des dieux et du monde, Paris, Société d' édition "Les Belles Lettres", 1960.

Sambursky, S., El Mundo Físico a fines de la antigüedad, Buenos Aires, EUDEBA, 1970.

STÄCKER, Thomas, Die Stellung der Theurgie in der Lehre Jamblichs, Frankfurt am Main, Peter Lang (Studien zur klassischen Philologie, 92), 1995.

Steel, Carlos "L'Âme: Modèle et Image", en H. J. Blumenthal et E. G. Clark, pp. 14-29.

Tapia Zúñiga, Pedro. Cfr. Plutarco.

Trouillard, Jean, "El Neoplatonismo", Brice Parain (dir.), Del mundo romano al islam medieval. Roma-Bizancio-El neoplatonismo-La filosofía judía medieval-La filosofía islámica, trad. Pilar Muñoz, José Ma. Álvarez y Pilar López Máñez, México, Siglo XXI (Historia de la Filosofía, 3), 1990 (10a. ed.), pp. 98-141.

VAN DER Horst, P. C., Les vers d'or pythagoriciens. Édités avec une introduction et un commentaire, Leyde, E. J. Brill, 1932.

Von Armin, H. (ed.), Stoicorum Veterum Fragmenta, 4 vols., Leipzig, Teubner, 1903-1905,

W achsmuth, C., and O. Hense (eds.), Stobaei Anthologii libri duo priores qui inscribi solent Eclogae physicae et ethicae, 5 vols., Berlin, 18841923.

Zeller, Eduard, y R. Mondolfo, La filosofia dei greci nel suo sviluppo storico. Parte III. La filosofia post-aristotelica. Volumen VI. Giamblico e la scuola di Atene (a cura di Giuseppe Martano, trad. Ervino Pocar), 1a. reimpr., Firenze, La Nuova Italia, 1968. 